\title{
RESUMEN.
}

El comportamiento que sufren las acciones se ve influenciado, en gran medida, por las contingencias económicas tanto nacionales como internacionales, pero también por diversos hitos económicos que pueden afectar al país en el cual se transan dichas acciones. Esta investigación consiste en analizar cuantitativamente la variación del valor de las acciones desde agosto 2005 a diciembre 2014, que experimentan las empresas de los distintos sectores industriales de Chile, frente a los principales hitos económicos que afectaron al país. Lo anterior con el objeto de dar validez empírica a la hipótesis planteada, la cual es que frente a un mismo hito económico el precio de las acciones experimenta las mismas variaciones en cada sector industrial. Esto se obtendrá a través del análisis de las variaciones mediante la correlación de los valores de las acciones publicados en la bolsa de valores, entre los periodos señalados. Del análisis de las acciones y resultados de las variaciones, se obtiene que no existió correlación en los grupos económicos. Un mismo hito económico no afectó de igual manera a todos los grupos de los diversos sectores industriales, rechazando la hipótesis planteada.

Palabras Claves: Valor accionario, contingencias económicas, correlación, sectores industriales e hitos económicos

\section{ANÁLISIS DE LA VARIACIÓN DEL VALOR DE LAS ACCIONES DESDE AGOSTO 2005 A DICIEMBRE 2014, EXPERIMENTADA POR EMPRESAS DE LOS DISTINTOS SECTORES INDUSTRIALES DE CHILE, FRENTE A LOS PRINCIPALES HITOS ECONÓMICOS QUE AFECTARON AL PAÍS.}

Nicole Hernández Norman / Shyrlie Muñoz Acosta

\section{ANALYSIS OF THE VARIATION OF THE STOCK SHARES' VALUE FROM AUGUST 2005 TO DECEMBER 2014 EXPERIMENTED BY COMPANIES OF DIFFERENT INDUSTRIAL AREAS OF CHILE, IN VIEW OF THE MAIN ECONOMICAL LANDMARKS WHICH AFFECTED THE COUNTRY.}

\begin{abstract}
The performance, which stock shares suffer, is not only related to a great extent by both the national and international economical contingency, but also by different economical landmarks that may affect the country where the stock shares are transacted. This research aims at analyzing quantitatively the variation of the stock shares 'value experimented by companies in different industrial areas of Chile from August 2005 to December 2014, in view of themain economical landmarks which affected the country. The above, with the aim of giving empyrical validity to the posed hypothesis which states that faced up to a same economical landmark, the stock shares' price experiments the same variations in each industrial area. To have the information, an analysis will be made of the variations on the basis of the correlation of the published stock shares 'prices in the stock exchange in the mentioned periods. From the analysis of stock shares and the results of their variations, it could be observed that there was no correlation in the economical groups. A same economical landmark did not affect in the same way to all the groups in the different industrial areas, thus rejecting the posed hypothesis.
\end{abstract}

Key Words: Stock shares' Value, economical contingencies, correlation, industrial areas and economical landmarks.

1 Alumnas Tesistas de la Carrera de Auditoría de la Universidad de Valparaíso, teniendo como profesor guía a la Profesora Dra. Karime Chahuán.Jiménez 
Revista de Investigación Aplicada en Ciencias Empresariales 


\section{PROBLEMA}

Existen diversos acontecimientos que han ocurrido, ya sea a nivel mundial como nacional, que han afectado la economía de Chile. Entre los cuales se pueden encontrar: Crisis Subprime, terremoto 2010 zona centro sur, terremoto 2014 norte chico, entre otros (Rodríguez, 2002).

En los últimos años se ha sido testigo de cómo una parte de los países a nivel mundial se vieron afectados por las distintas crisis económicas que han ocurrido entre los años 2004 al 2014. Debido a esto, Chile se encuentra dentro de los países más afectados de Latino América (Caputo, 2009). Sin embargo, no solo las crisis pueden afectar la situación económica de los países, sino que existen otros factores que también pueden influir. Entre estos se puede destacar los Desarrollos Internos; Sucesos Mundiales; Inflación y Tasa de Interés; Tasa de Cambio; Despliegue Publicitario; entre otros (Wolski, 2014).

La presente investigación consiste en un análisis de la variación del valor de las acciones desde agosto 2005 a diciembre 2014 experimentada por empresas de los distintos sectores industriales de Chile, frente a los principales hitos económicos que afectaron al país.

\section{MARCO TEÓRICO}

\section{Aspectos Generales}

La presente investigación comprende el estudio del mercado de capitales, el cual se enfocará principalmente en el mercado de valores y la forma en que las empresas ven sus acciones vulneradas a través de alzas o bajas en su valor. Para ello se plantearán los principales hitos económicos que se desarrollaron, tanto a nivel mundial como nacional, y que puedan ser involucrados como consecuencias de dichas variaciones en las acciones.

\section{Mercado de Capital}

El mercado de capitales es aquél en que se coordinan la oferta y la demanda de capital financiero en sus más variadas formas (dinero y valores 0 activos financieros), surgiendo intermediaros especializados, regulados y controlados. Es decir, es el conjunto de regulaciones, instituciones, prácticas e individuos que forman una infraestructura tal que permite a los oferentes de recursos vender dichos recursos a los demandantes de estos. (Ministerio de Hacienda, 2015) 
Atendiendo a las formas que asume el capital, el mercado de capitales se puede clasificar en mercado financiero y mercado de valores. El mercado financiero es aquel donde existen oferentes y demandantes de dinero. Por su parte, el mercado de valores es aquél en el que se ofrece y demanda todo tipo de valores mobiliarios (Ministerio de Hacienda, 2015).

En particular el mercado de capitales chileno se organiza en tres grandes sectores clasificados de acuerdo al regulador encargado de su supervisión:

1. El de las administradoras de fondos de pensiones, quienes reciben recursos de los cotizantes o trabajadores y ofrecen estos recursos al mercado principalmente a través de la compra de bonos, es decir, compra de deuda.

2. El de los bancos, quienes demandan recursos de los depositantes y ofrecen recursos al mercado a través de créditos principalmente.

3. El mercado de los valores y seguros, que agrupa a todas las instituciones que transan valores de oferta pública entre estas a las administradoras de fondos mutuos y de inversión, las bolsas de valores, los corredores y agentes de valores, los depósitos de valores, etcétera, y a las compañías de seguros (Ministerio de Hacienda, 2015).

\section{Mercado de Valores}

"El mercado de valores está constituido por todas aquellas operaciones en las que se transan instrumentos de carácter transferible, independientemente del plazo al cual se realicen" (Bolsa de Comercio de Santiago, 2015: 1). En el mercado de Valores, los inversionistas buscan instrumentos financieros en los cuales invertir y las empresas requieren financiar sus proyectos. Ambos negocian valores, tales como acciones, bonos y fondos mutuos, a través de intermediarios. Y éste opera como cualquier otro mercado en el que se transan bienes, solo que en este caso se trata de instrumentos financieros. La demanda y la oferta se producen en un lugar de intercambio llamado mercado, en el que la compra y venta se puede realizar a través de intermediarios, ya sea en una Bolsa o fuera de ella, y en otros casos entre las partes interesadas. Los inversionistas buscan los instrumentos financieros que les reporten la mayor rentabilidad posible de acuerdo al riesgo que estén dispuestos a asumir. Los emisores requieren de capital para financiar sus proyectos, para reunir estos recursos pueden utilizar la vía de ofrecer valores (acciones, bonos, etc.) a los inversionistas (Bolsa de Comercio de Santiago, 2015). 
Según la SVS (2015), los entes que participan en el Mercado de Valores son:

1. Emisores de Valores: ofrecen valores (acciones, bonos, cuotas de fondos mutuos, etc.) para su venta en el mercado.

2. Demandantes de Valores: personas o instituciones que desean obtener ganancias mediante la adquisición de instrumentos de inversión. Por la naturaleza existen dos tipos de inversionistas: Institucionales y Privados.

\section{Tipos de Mercados de Valores}

Mercado Bursátil: Es aquel que comprende todas aquellas operaciones que son organizadas y reglamentadas por instituciones formales y especializadas, denominadas Bolsas de Valores (Bolsa de Comercio de Santiago, 2015).

Mercado Fuera de la Bolsa: Está constituido por aquellas operaciones que se realizan fuera de los recintos bursátiles. Estas transacciones son efectuadas por intermediarios que actúan en forma paralela a los corredores de Bolsa, entre los que destacan: Sociedades Financieras y Bancarias, Agentes de Valores. (Bolsa de Comercio de Santiago, 2015)

\section{Riesgo Sistemático y No Sistemático}

Riesgo Sistemático: "Es aquel que se deriva de la incertidumbre global del mercado que afecta en mayor o menor grado a todos los activos existentes en la economía. Es importante tener en cuenta que, dada la incertidumbre asociada con la economía en agregado, este riesgo no puede eliminarse mediante la diversificación; de ahí, que también se le denomine riesgo de mercado". (Segorb, 2014).

Riesgo No sistemático: El riesgo diversificable se debe a hechos aleatorios: demandas judiciales, huelgas, programas exitosos y fallidos de marketing, ganar o perder un contrato y otros que son peculiares de le empresa. Dado que tiene un carácter aleatorio, sus efectos en el portafolio pueden eliminarse diversificando, es decir, los sucesos negativos de una compañía serán compensados con los sucesos positivos (Brigham, Houston, 2005: 188).

Entre la principal diferencia que surge entre estos dos tipos de riesgo se puede 
mencionar que el sistemático se puede definir como cualquier riesgo que afecte en mayor 0 menor medida a un gran número de activos. En cambio el riesgo no sistemático es un riesgo que afecta en forma específica a un solo activo 0 a un pequeño grupos de ellos. (Ross,Westerfield, Jaffe, 2009: 303).

\section{Instrumentos Financieros}

La SVS (2015) los define como: "Cualquier título transferible, como acciones, instrumentos de deuda de corto, mediano y largo plazo, cuotas de Fondos Mutuos, cuotas de Fondos de Inversión y en general, todo título de crédito e inversión". Por lo general los instrumentos financieros se pueden clasificar en:

1. Renta Fija: Los instrumentos de renta fija son emitidos por entidades privadas o públicas con el objetivo de obtener recursos. La renta fija son títulos que representan obligaciones donde se adquiere un compromiso de devolución de capital y además el pago de intereses, pueden ser a mediano y largo plazo, pero también pueden ser a un plazo indefinido (SVS, 2015).

2. Renta Variables: Los instrumentos de renta variable son instrumentos representativos de capital, que se caracterizan por tener un alto riesgo y un retorno que está ligado a las utilidades obtenidos por la empresa en la cual se invirtió y por las ganancias de capital obtenidas por la diferencia entre el precio de compra y venta (Bolsa de Santiago, 2015).

Acciones: Las acciones son instrumentos de renta variable emitidos por sociedades anónimas, que representan un título de propiedad sobre una fracción del patrimonio de la empresa, es decir, el comprador de una acción o accionista pasa a ser propietario de una parte de la empresa emisora. Desde el punto de vista de la empresa que las emite, las acciones son una alternativa de financiamiento para conseguir recursos a plazo indefinido. En cambio desde el punto de vista del accionista, las acciones son una alternativa de ahorro a corto, mediano 0 largo plazo, o bien a plazo indefinido, según sean las razones que motivan su compra (Bolsa de Comercio de Santiago, 2015).

De acuerdo a lo que señala la Bolsa de Santiago (2011) existen diversos tipos de acciones, las que pueden ser transadas, compradas 0 vendidas:

1. Acciones Ordinarias: Son acciones que confieren iguales derechos 
a los socios o accionistas, en cuanto a voto y recibir un dividendo con base en las utilidades actuales, previa aprobación por parte de la asamblea (Bolsa de Comercio de Santiago, 2015).

2. Acciones Preferenciales: Tipo de acción que otorga el derecho a voto sólo en las asambleas generales o extraordinarias de accionistas. Se denominan "Preferenciales", dado que según la Ley se les debe otorgar prelación en el pago de utilidades y del patrimonio social, en el caso de liquidación, respecto de las acciones ordinarias (Bolsa de Comercio de Santiago, 2015).

3. Acciones a la Orden: Son las transmisibles mediante la entrega del título debidamenteendosado porsutitular(BolsadeComerciodeSantiago, 2015).

4. Acciones al Portador: Son las suscritas anónimamente. Pueden ser traspasadas por simple compraventa en una bolsa de valores. Otorgan a su poseedor el carácter de socio en la proporción por ellas representadas. Se transmiten por la simple entrega del título (Bolsa de Comercio de Santiago, 2015).

\section{Principales Hitos Económicos entre los años 2004 al 2014 Acontecimientos Macroeconómicos Burbuja Inmobiliaria (2007):}

La crisis hipotecaria del 2007 se desencadenó en el instante en que los inversores percibieron señales de alarma. El incremento gradual del interés por parte de la Reserva Federal, así como el incremento natural de las cuotas de esta clase de créditos hicieron aumentar la tasa de morosidad y el nivel de embargos y no solo en las hipotecas de alto riesgo. Debido que importantes instituciones bancarias y grandes entidades de inversión tenían comprometidos sus activos en este tipo de transacciones indujo una imprevista contracción del crédito y una enorme volatilidad de los valores bursátiles, generándose desconfianza y pánico en el inversionista. Así como también, una repentina caída de las bolsas de valores de todo el mundo, como consecuencia de la falta de liquidez. Cuando estalló la crisis en agosto del 2007, se estimaba que había una morosidad acumulada de más de 500.000 millones de dólares en el mercado de las hipotecas. Pero mucho mayor era la pérdida de valor de los títulos y acciones que estaban respaldados por las entonces bautizadas "hipotecas basura". En otras palabras, muchos de los bancos 
vinculados al negocio inmobiliario no pudieron afrontar sus deudas porque se evaporaron sus activos, apalancados en hipotecas incobrables y desvaluadas. Y en esa compleja trama financiera, el efecto dominó empezó a arrastrar a la quiebra a muchas entidades relacionadas de algún modo con estos instrumentos financieros apoyados en una frágil burbuja (Hernández, Moraleda, Sánchez, 2011).

La crisis financiera es resultado de la incapacidad de pago de los préstamos hipotecarios de miles de personas que tenían créditos Sub-Prime. Muchos de ellos contratados con pago de sólo intereses o con opciones de amortización negativa, que al cambiar a préstamos totalmente amortizados propició el incremento de los pagos a realizar dejando sin posibilidad de pagar a los deudores, que de por si tenían un pobre historial crediticio y una nula capacidad de pago, lo cual ya se sabía (Barcelata, 2010).

\section{Crisis Financiera Subprime (2008):}

La crisis financiera mundial de fines del 2008 fue una de las peores desde la Gran Depresión y ha dado lugar a un crash bursátil histórico, se convirtió visible con la quiebra, fusión o rescate de varias entidades financieras importantes en los Estados Unidos. Las causas subyacentes a la crisis son la inestabilidad financiera de los principales bancos de inversión, empresas de seguros y entidades hipotecarias. Posteriormente, ha surgido el temor a una profunda recesión de carácter global. A partir de octubre de 2008, las Bolsas de Estados Unidos, Europa y la región Asia-Pacífico cayeron aproximadamente un $30 \%$ desde el comienzo del año (Pérez, 2008).

La crisis financiera de 2008, causó una marcada reducción del crecimiento mundial, el comercio y el acceso a financiamiento para los países en desarrollo (Banco Mundial, 2015).

Hubo grandes descensos en los mercados de valores de todo el mundo durante 2008. Las múltiples crisis simultáneas que afectaron al sistema financiero de Estados Unidos, causaron fuertes pérdidas en los mercados de todo el mundo, provocando el pánico entre los inversores y ahorradores, al verse afectado el sistema bancario. Se establecieron records para numerosos indicadores de riesgo y temor de los inversores, como el TED spread, los rendimientos del Tesoro y el precio del oro. La inestabilidad financiera al parecer comenzó con las hipotecas Subprime, pero se ha visto agravada por diversos condicionantes económicos, como lo son: bajada de 
precios de la vivienda, subida de precios en los productos básicos, disminución del consumo, pérdida de empleos, dificultad de los exportadores para obtener créditos y aumento de la inflación (Pérez, 2008).

\section{Crisis Europea (2010):}

La crisis de la deuda europea se desencadenó por una serie de acontecimientos en el sector bancario de Estados Unidos. Cuando la ralentización de la economía de Ios Estados Unidos impidió a gran número de propietarios americanos reembolsar sus hipotecas, bancos de todo el mundo que tenían inversiones relacionadas con esas hipotecas empezaron a perder dinero (Comisión Europea, 2014).

Lehman Brothers, uno de los bancos más importante de ese país, se hundió bajo el peso de sus inversiones desacertadas, alarmando a otros bancos e inversores con los que había hecho operaciones comerciales. El temor de que pudieran quebrar más bancos hizo que inversores y banqueros llevaran al extremo las precauciones. Los bancos dejaron de prestarse dinero entre sí, poniendo en graves dificultades a los que dependían de los préstamos. Los bancos europeos que habían hecho grandes inversiones en el mercado hipotecario estadounidense sufrieron un duro golpe. Para evitar la quiebra de algunos bancos, los gobiernos de muchos países acudieron a la ayuda de Alemania, Francia, Reino Unido, Irlanda, Dinamarca, Países Bajos y Bélgica, pero el costo del rescate resultó ser muy elevado. En 2009, cuando Europa entró en recesión, el problema que al principio afectaba a los bancos, empezó a extenderse a los gobiernos. Los inversores empezaron a observar más detenidamente las finanzas estatales. Grecia fue objeto de atención ya que su economía se encontraba en malas condiciones y los gobiernos sucesivos habían acumulado deudas equivalentes a casi el doble del volumen de la economía (Comisión Europea, 2014).

Los gobiernos de los países de la Eurozona han instrumentado alternativas de solución que, en lugar de solucionar la crisis, la han profundizado. Las medidas adoptadas se han expresado principalmente como reducciones del gasto público, afectando programas sociales. La austeridad impuesta, complementándose con la reducción de ingresos de la población se ha traducido en aumento del desempleo, pobreza y desigualdad puesto que la reducción de puestos de trabajo privados se ha agregado los recortes de la ocupación gubernamental. El resultado es mayor que la reducción de la demanda agregada, reforzándose con ello la reducción del nivel de actividad (Blas, 2013). 


\section{Desaceleración en China (2012):}

La economía de China se desaceleró a su ritmo más fuerte en los dos primeros meses del año desde la crisis financiera global, lo que aumentaba el temor de que esta desaceleración podría socavar el crecimiento mundial. La producción industrial de China se expandió un 6,8 por ciento en enero y febrero respecto al año anterior. Fue la cifra más baja desde 1990 y todos los indicadores apuntan a que el descenso continuará. La crisis iniciada el año 2008 comienza a golpear a la economía exportadora más grande del mundo (Moreno, 2014).

Según Foley (2013) la desaceleración de China se debe en primer lugar, a que la demanda por las exportaciones de China se está desacelerando. La disminución de $3 \%$ en junio es especialmente débil, pero el aumento promedio durante los últimos doce meses es la tasa más baja desde principios de 2010. En segundo lugar, la gravedad económica está alcanzando al país. La mano de obra china ya no está aumentando y el ritmo de la urbanización se está desacelerando debido a que muchas personas ya han abandonado las granjas. Algo más preocupante es el rendimiento decreciente de la inversión. El crecimiento de China ha sido impulsado por los préstamos, pero no hay señales que indiquen que la desaceleración haya sido causada por una contracción del crédito (Foley, 2013). Sin embargo, la economía china no era inmune a la crisis global. La fuerte caída del comercio mundial hundió sus exportaciones y el estado de nuevo intervino con inversiones masivas en infraestructura. Se buscó mantener la economía en marcha, aunque a un ritmo más lento que antes. Esto generó una acumulación de exceso de capacidad en toda la economía, especialmente en la construcción y la industria pesada. Siguiendo a los ideólogos de la Escuela de Chicago, se buscó expandir la oferta. Pero la teoría de la oferta ha sido sepultada completamente. Este exceso de capacidad (oferta) de China también lo tiene Japón, Alemania, Estados Unidos. Todos los países industrializados acusan hoy un exceso de capacidad y operan a razón de 70 por ciento (Moreno, 2014).

\section{Catástrofes Naturales}

\section{Terremoto en Aysén (2007):}

El 21 de abril de 2007 a las 13:53 horas, un sismo de magnitud $6.3^{\circ}$ escala de Richter hace que muchas personas salgan corriendo a las calles, luego de que sintieran un inusual y violento movimiento sísmico, que se originó en el fondo 
del fiordo Aisén, provocando deslizamiento en los cerros circundantes lo que hizo levantar gigantescas olas, que causaron estragos en varios puntos costeros del lugar evento inusual en la zona (Sismo24, 2014). La catástrofe ocurrida en Aysén dejó diez fallecidos y provocó daños menores en infraestructura. (Biblioteca Nacional de Chile, 2014).

\section{Terremoto en Tocopilla (2007):}

El 14 de noviembre del 2007 a las 12:47 horas un terremoto afectó a Tocopilla, el cual tuvo una magnitud de 7,7 grados en la escala de Richter. El epicentro se ubicó a 35 kilómetros al este de la ciudad y a 59 kilómetros de profundidad. Aunque no hubo tsunami, como resultado del violento sismo en donde dos mujeres murieron, 2.600 casas quedaron en el suelo y 4 mil personas resultaron damnificadas. El movimiento telúrico también se sintió con fuerza en Antofagasta, Arica, Iquique, Calama y Copiapó (Emol, 2014). Además, se vivieron graves problemas de abastecimiento de agua potable durante varios días, ocasionando la molestia de sus 22 mil habitantes (Biblioteca Nacional de Chile, 2014).

\section{Erupción Volcán Chaitén (2008):}

En la madrugada del 2 de mayo de 2008, el volcán Chaitén, situado en la X Región de Los Lagos en Chile, a 10 kilómetros de la localidad del mismo nombre, entró en erupción. Al entrar en actividad en 2008, el volcán provocó temblores y el desplazamiento de un enorme alud de arena y ceniza. Arrasó con la pequeña ciudad, desbordó el cauce natural del río Blanco y buscó como destino final las aguas del océano Pacífico. En su avance, el alud empujó hacia el mar una parte de la ciudad. La otra parte fue cubierta por la arena y la ceniza volcánica. (Interpatagonia, 2015)

\section{Terremoto y tsunami en Centro Sur (2010):}

Se registra un fuerte sismo ocurrido a las 03:34:17 hora local (UTC-3), del sábado 27 de febrero de 2010, que alcanzó una magnitud de 8,3 MW de acuerdo al Servicio Sismológico de Chile y de 8,8 MW según el Servicio Geológico de Estados Unidos. El epicentro se ubicó en la costa frente a las localidades de Curanipe y Cobquecura. El sismo, tuvo una duración de cerca de 2 minutos 45 segundos. Fue percibido en gran parte del Cono Sur con diversas intensidades, desde Ica en Perú por el norte hasta Buenos Aires y Sao Paulo por el oriente. Las zonas más afectadas por el terremoto fueron las regiones chilenas de Valparaíso, Metropolitana de Santiago, O’Higgins, Maule, Biobío y La Araucanía. Las víctimas fatales llegan a más de 450. 
Cerca de 500 mil viviendas con daño severo y se estiman un total de 2 millones de damnificados, en la peor tragedia natural vivida en Chile desde 1960. El sismo es considerado como el segundo más fuerte en la historia del país y uno de los cinco más fuertes registrados por la humanidad. (Aquevedo, 2014).

\section{Terremoto de Constitución (2012):}

El domingo 25 de marzo del 2012 a las 19:37 horas millones de chilenos se despertaron asustadas, un fuerte ruido procedente del centro de la tierra desataba las alarmas entre las regiones de Coquimbo y la Araucanía. Un nuevo movimiento sísmico sacudía las regiones centrales de Chile, según el Servicio Geológico de Estados Unidos registró una magnitud de 7,1 grados. No obstante, el Servicio Sismológico de la Universidad de Chile indica que el sismo fue de 6.8 (CNN, 2015). El epicentro fue a $35 \mathrm{~km}$ de profundidad en la región del Maule, a $32 \mathrm{~km}$ al noroeste de Talca, 215 km el noreste de Concepción y 215 km al suroeste de Santiago (CNN, 2015). El temblor se dejó sentir desde la región de Coquimbo hasta la región de Los Lagos, siendo la Región del Maule la más afectada y provocando alta conmoción en las regiones de 0'Higgins y del Biobío, fuertemente afectadas por el violento terremoto de 2010 (CNN, 2015).

\section{Terremoto Norte Grande (2014):}

A las 20:46 horas del $1^{\circ}$ de abril del 2014 en Norte Grande se sacudieron violentamente. Un sismo de 8.2 grados con epicentro en el fondo marino cercano a Iquique causaba estragos y víctimas. Minutos después autoridades SHOA-ONEMI alertaron a la población costera nacional e insular de la posibilidad que se generará un maremoto menor, lo que ocurrió afectando principalmente la bahía de lquique. El día 2 a las 23:43 otro terremoto de 7.6 grados causa pánico en la población y más daños en Alto Hospicio, la costa nacional debió evacuar por segunda vez. Con la luz de día se pudo observar cuantiosos daños en varios poblados del interior. Además, caminos cortados y falta de servicios básicos (Sismo24, 2014). 


\section{PROPUESTA METODOLÓGICA}

Este estudio es de tipo cuantitativo con alcance correlacional basado en la información de la variación bursátil de las acciones y los diversos hitos que han afectado la economía chilena. Se utilizó el Método Analítico, a través del cual se busca identificar y describir los principales hitos económicos a nivel mundial y nacional, que puedan tener algún impacto en la valorización de las acciones de las empresas con mayores transacciones bursátil según la Bolsa de Comercio de Santiago de Chile entre los años 2004 al 2014, se seleccionaron tres empresas por cada sector, y se clasificaron según el sector industrial que pertenezcan, dado a la categoría sectorial bursátil que especifica la Bolsa y Mercados Españoles. Para identificar los principales hitos económicos se realizó una recopilación de información y una investigación de antecedentes históricos en la web. Luego de obtener la información se pudo analizar mediante gráficos de dispersión la fluctuación de las acciones y su comportamiento frente a cada hito económico. Posteriormente se realizó una prueba no paramétrica "Kolmogorov-Smirnov" que proporcionará los resultados de normalidad para saber qué tipo de coeficiente de correlación se deberá aplicar a la variación del valor bursátil de las acciones. Las dos alternativas son: para una muestra con comportamiento normal Pearson y para una muestra con comportamiento no normal se aplicará Kendall.

HIPÓTESIS: Frente a un mismo hito económico el precio de las acciones experimenta las mismas variaciones en cada sector industrial.

\section{ANÁLISIS DE RESULTADOS}

Se seleccionaron 3 empresas con mayor transacción en la bolsa por cada sector industrial según la clasificación sectorial bursátil que especifica la Bolsa y Mercados Españoles. Se señala que existen 6 sectores básicos (BME, 2015: 4):

\section{Clasificación Sectorial Bursátil}

1. Petróleo y energía

1.1. Petróleo

1.2. Electricidad y Gas

1.3. Agua y otros

1.4. Energías renovables 
2. Materiales básicos, industria y construcción

2.1. Minerales, metales y transformación productos metálicos

2.2. Fabricación y montaje de bienes de equipo

2.3. Construcción

2.4. Materiales de construcción

2.5. Industria química

2.6. Ingeniería y otros

2.7. Aeroespacial

3. Bienes de consumo

3.1. Alimentación y bebidas

3.2. Textil, vestido y calzado

3.3. Papel y artes gráficas

3.4. Automóvil

3.5. Productos farmacéuticos y biotecnología

3.6. Otros bienes de consumo

4. Servicios de consumo

4.1. Ocio, turismo y hostelería

4.2. Comercio

4.3. Medios de comunicación y publicidad

4.4. Transporte y distribución

5. Servicios financieros e inmobiliarias

5.1. Bancos y cajas de ahorros

5.2. Seguros

5.3. Sociedades de cartera y holdings

5.4. SICAV

5.5. Inmobiliarias y otros

5.6. Servicios de inversión

5.7. Fondos cotizados

5.8. Capital riesgo

5.9. Instituciones de inversión libre

5.10. SOCIMI

6. Tecnología y Telecomunicaciones

6.1. Telecomunicaciones y otros

6.2. Electrónica y software

6.3. Hardware tecnológico y equipamiento 


\section{Análisis del Sector Petróleo y Energía}

Primer Sector Económico: empresas Colbún, Endesa y Enersis (2005-2014)

\section{COLBÚN}

Gráfico 1: Comportamiento de las acciones de Colbún.

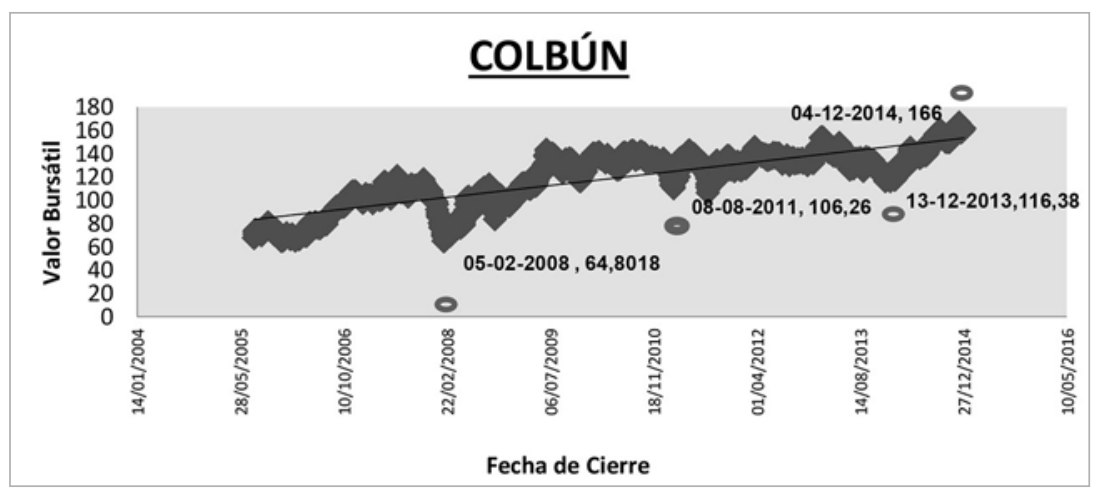

Fuente: Elaboración propia en base a la información proporcionada por la Bolsa de Comercio de Santiago.

2005: La industria enfrentó la peor crisis de largo plazo generada por las restricciones al suministro de gas natural (argentinas), el aumento del precio del petróleo y la disminución de inversiones en el sector hacían presagiar una escasez difícil de revertir.

2006: Aumento significativo del costo del gas natural por el aumento de las retenciones del precio impuestas por las autoridades argentinas. También fue el primer año de operación de la compañía fusionada con Endesa para desarrollar el Proyecto Aysén.

2007: Fue un ejercicio complejo, se reflejó en un flujo de caja insatisfactorio y una pérdida del ejercicio. Si bien los ingresos crecieron como consecuencia de los aumentos de precio, no fue suficiente para compensar los gastos en compras de petróleo y de energía.

2008: Lluvias de invierno permitieron recuperar el nivel del embalse y generar casi a plena capacidad en las centrales hidráulicas. Las mejores condiciones hidrológicas apoyaron los resultados del tercer trimestre y la fuerte baja de los precios de combustibles.

2009: Iniciaron la aplicación de las NIIF y adoptaron como moneda funcional el dólar de los EE.UU. Pudieron estructurar los mercados de derivados para proteger el flujo de caja cubriendo los riesgos ante posibles alzas en el precio del petróleo. 
2010: El terremoto cortó el suministro eléctrico en todo el Sistema Interconectado Central por horas, los efectos en los activos fueron menores considerando la magnitud del evento. En agosto se perfeccionó un acuerdo de suministro de gas natural proveniente de gas natural licuado (GNL) para Colbún S.A. con Enap Refinerías S.A.

2011: El Ministerio de Energía publicó un decreto de racionamiento eléctrico, con el fin de tomar medidas de forma anticipada para evitar situaciones de estrechez energética y cortes de suministro durante el año. El precio del petróleo alcanzó un promedio anual de 95 US\$ por barril en comparación a los 80 US\$ del año anterior.

2012: Chile crece con fuerza y también lo hace la demanda de la energía eléctrica. La línea de impuestos tuvo un cargo no recurrente producto de la Reforma Tributaria, la que incrementó la tasa impositiva para las empresas a $20 \%$ en forma permanente.

2013: La empresa refinanció toda la deuda de corto plazo vía un crédito sindicado a tasas y plazos muy atractivos. Estuvo marcado por condiciones hidrológicas que continuaron siendo desfavorables y extremadamente secas por cuarto año.

2014: Marcado por condiciones hidrológicas levemente más favorables, esto se explica porque los deshielos fueron superiores, sumado a que la nueva central hidroeléctrica Angostura generó de manera consistente y confiable, aportando 1.301 GWh en el año.

\section{ENDESA}

Gráfico 2: Comportamiento de las acciones de Endesa.

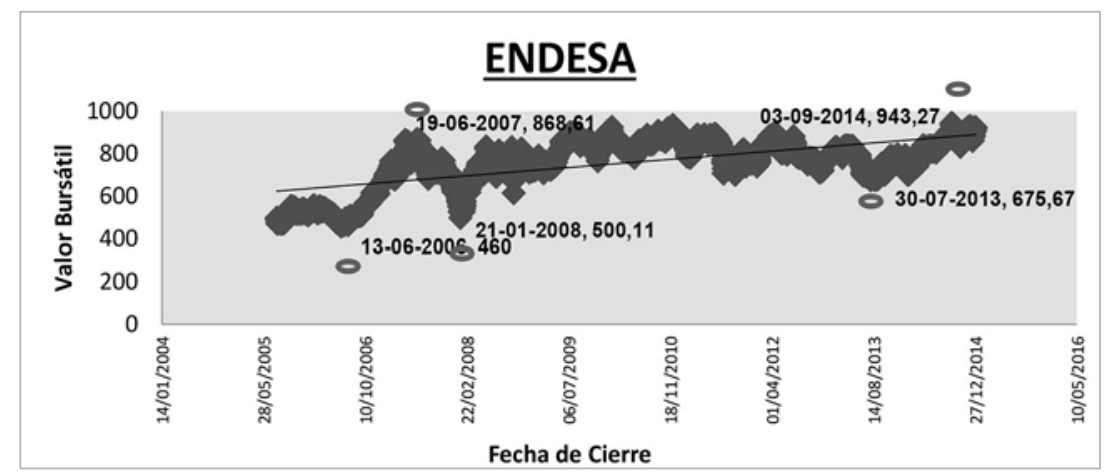

Fuente: Elaboración propia en base a la información proporcionada por la Bolsa de Comercio de Santiago. 
2005: Se manifestó la escasez de gas natural en un escenario de crecimiento de la demanda energética.

2006: La entidad se asocia con la industria, Colbún S.A., para proyectos hidroeléctricos de la XI Región de Aysén. La compañía, en conjunto con Enap y Metrogas, firma el acuerdo del proyecto GNL, para independizar el sistema eléctrico chileno.

2007: Tuvo que desembolsar un mayor costo producto de la menor hidrología y la escasez de gas natural tanto en Chile como en Argentina, y por un menor resultado basado, en una provisión de $\$ 48.890$ millones por la posible pérdida patrimonial de Gas Atacama.

2008: Marcado por un escenario de severa estrechez energética. Entró en operación comercial la minicentral hidroeléctrica de pasada Ojos de Agua, de la filial Endesa Eco.

2009: Según estudios, la demanda eléctrica aumentaría un 6\% anual durante las próximas dos décadas, considerando solo el Sistema Interconectado Central (SIC).

2010: El escenario energético tiene una de las peores sequías de las últimas cuatro décadas. Se presentó un incremento de 30,3\% en los costos de aprovisionamientos y servicios, debido a mayores compras de energía y a un aumento del costo de transporte.

2011: Endesa anotó un descenso que tuvo como causas los mayores costos por consumo de combustibles en Argentina, Chile y Perú, y el aumento en el ítem Otros Gastos Fijos de Explotación, producto de Impuesto al Patrimonio en Colombia.

2012: Nuevamente se vivió los efectos de una prolongada sequía, la cual, afectaró negativamente los resultados de la entidad. Otro aspecto que impactó negativamente en el resultado fue el efecto de la quiebra de Campanario.

2013: El país comenzó a experimentar una desaceleración del ritmo de crecimiento y la generación hidroeléctrica se vio afectada por la sequía.

2014: Este año la entidad realizó una provisión por HidroAysén, debido a que la recuperación de la inversión realizada depende de decisiones judiciales y de definiciones de la Agenda de Energía adoptadas por el país. 


\section{ENERSIS}

Gráfico 3: Comportamiento de las acciones de Enersis.

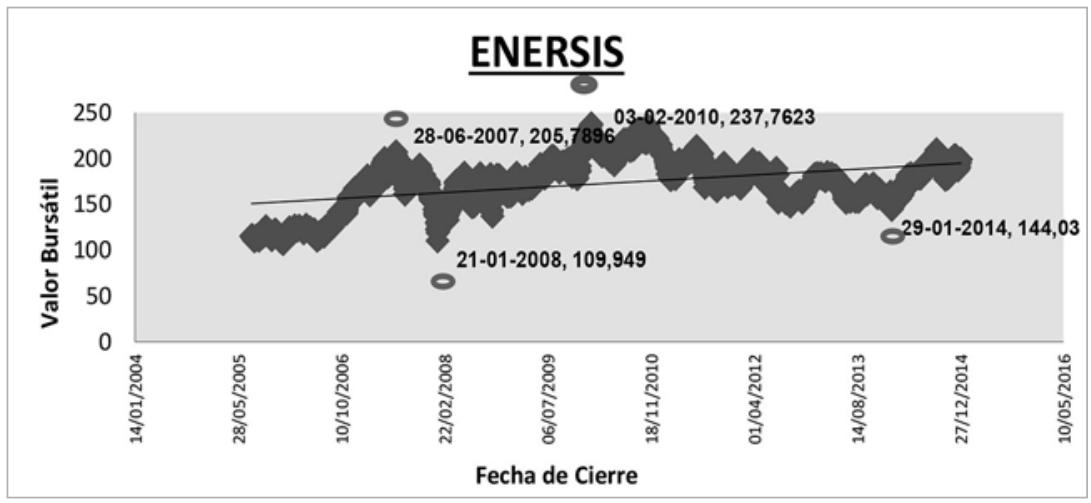

Fuente: Elaboración propia en base a la información proporcionada por la Bolsa de Comercio de Santiago.

2005: Se construye la nueva sociedad anónima Endesa Brasil S.A., consolidada por Enersis. Los gastos de explotación aumentan y es posible que se tengan que realizar compras de electricidad a terceros con el fin de cumplir con los compromisos.

2006: Un hecho significativo lo constituye el crecimiento alcanzado en la rentabilidad del patrimonio, que se situó en torno a un $10 \%$, un año atrás era de tan sólo un 2,6\%.

2007: Importante alza en el precio de los combustibles, uno de los períodos más secos de los últimos 50 años y un incremento de las restricciones de gas natural argentino.

2008: La sequía afectó al país durante los primeros meses del ejercicio, a las restricciones de gas natural y a la salida que sufrió una de las principales centrales térmicas. La falta de liquidez y confianza impactó la economía, dependiendo del sector en el cual se desenvuelvan cada una de las compañías.

2009: Caída de la actividad económica en los principales mercados. La matriz ENDESA vivió un largo proceso de OPAs, proceso que culminó cuando el Grupo ENEL pasó a controlar el 92,06\% del capital social, luego de adquirir el 25,01\% que poseía ACCIONA.

2010: Los principales hitos que impactaron el negocio fueron los efectos del terremoto en Chile, la sequía que vivió el mercado colombiano y chileno, y las 
condiciones climáticas inusuales que se presentaron en Brasil y Argentina.

2011: La economía mundial aún no se recuperaba de los vaivenes de la crisis Subprime, cuando se comenzó a sentir los efectos de la crisis que arrastran los países de la Unión Europea, detonando de manera clara la crisis de deuda soberana.

2012: Acontecimientos externos como la sequía, cambios regulatorios y acontecimientos de las economías europeas. Se aprobó con $81,94 \%$ del total de las acciones, la propuesta de aumento de capital.

2013: Aumento de capital se concluyó en marzo, colocándose el 100\% de las acciones disponibles para ser suscritas.

2014: El año anterior estuvo marcado por la desaceleración en el ritmo del crecimiento en América Latina. Esta situación se expresó en Chile y en la mayoría de las economías de la región, debido a los altos precios alcanzados en los mercados internacionales por este tipo de bienes.

Aplicación y Análisis prueba de Kolmogorov-Smirnov para Sector Petróleo y Energía. Cuadro 4: Prueba de Kolmogorov-Smirnov del Sector Petróleo y Energía

\begin{tabular}{|ll|r|r|r|}
\multicolumn{5}{|c|}{ Prueba de Kolmogorov-Smirnov para una muestra } \\
\hline & & COLBUN & ENDESA & ENERSIS \\
\hline $\mathrm{N}$ & & 2347 & 2347 & 2347 \\
Parámetros & Media & 118,445 & 755,740 & 172,551 \\
normales $^{\mathrm{a}, \mathrm{b}}$ & Desviación & 23,852 & 117,736 & 28,019 \\
& estándar &, 142 &, 123 &, 072 \\
Máximas & Absoluta &, 077 &, 089 &, 072 \\
diferencias & Positivo &,- 142 &,- 123 &,- 071 \\
extremas & Negativo &, 142 &, 123 &, 072 \\
Estadistico de prueba &, $112^{\mathrm{c}}$ &, $090^{\mathrm{c}}$ &, $118^{\mathrm{c}}$ \\
Sig. asintótica (bilateral) & & & \\
\hline
\end{tabular}

Fuente: Elaboración propia en base a la información proporcionada por la Bolsa de Comercio de Santiago.

Puesto que el valor del nivel crítico (Sig. Asintótica bilateral) es mayor a los grados de significancia $(0,05)$, se acepta la hipótesis de normalidad para el Sector Petróleo y Energía y se concluye que la muestra se ajusta a una distribución normal donde la prueba más acorde a esta distribución es la de Pearson. 


\section{Aplicación y Análisis prueba de Pearson para Sector Petróleo y Energía.}

Cuadro 5: Prueba Correlación Pearson del Sector Petróleo y Energía.

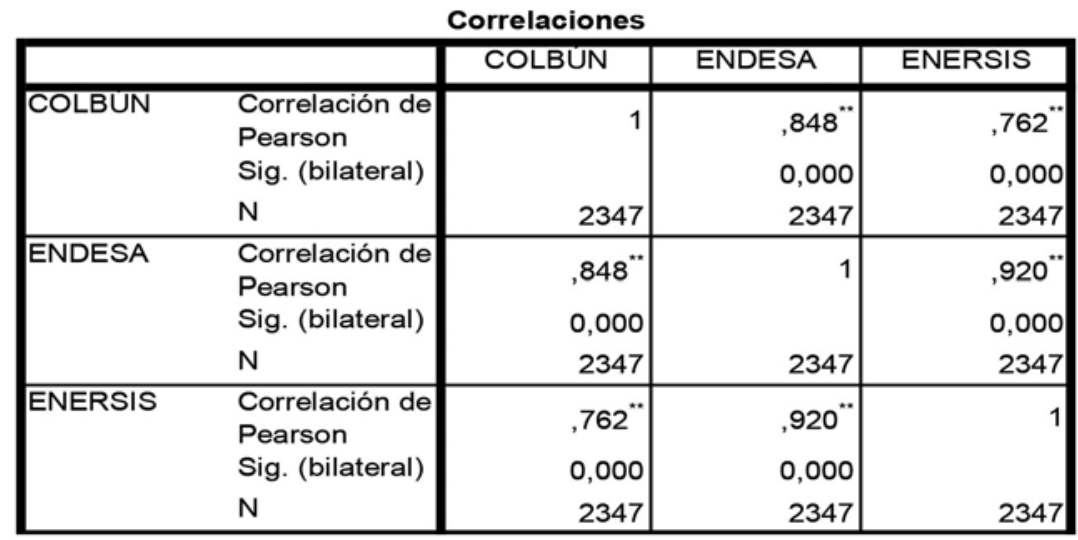

Fuente: Elaboración propia en base a la información proporcionada por la Bolsa de Comercio de Santiago.

A continuación, se presentan los parámetros para la investigación, que servirán para la interpretación de los resultados obtenidos en la Prueba de Correlación Pearson para el Sector Petróleo y Energía. Al comparar COLBÚN con ENDESA, se obtiene un índice de correlación de 0,848 , el cual indica que existe correlación entre el valor de las acciones.

Al comparar COLBÚN con ENERSIS, se obtiene un índice de correlación de 0,762, el cual indica que existe correlación entre el valor de las acciones. Y por último al comparar ENDESA con ENERSIS, se obtiene un índice de correlación de 0,920, el cual indica que existe correlación entre el valor de las acciones. 


\section{Análisis del Sector Materiales Básicos, Industria y Construcción.}

Segundo Sector Económico: empresas Besalco, CMPC y SQM (2005-2014)

\section{BESALCO}

Gráfico 4: Comportamiento de las acciones de Besalco.

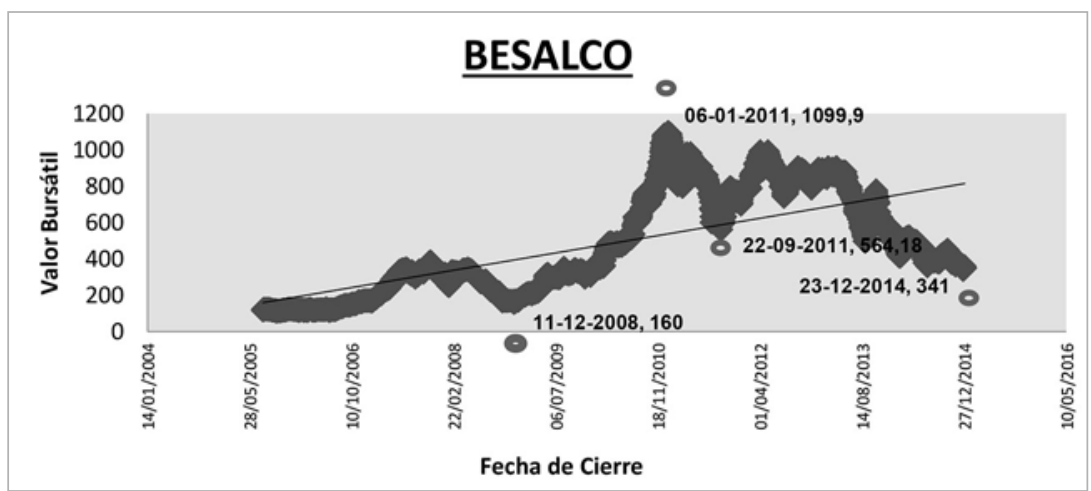

Fuente: Elaboración propia en base a la información proporcionada por la Bolsa de Comercio de Santiago.

2005: Los resultados de la compañía alcanzaron a MM\$6.752, después de impuesto con un incremento del $7 \%$ respecto del año anterior y, un retorno sobre patrimonio promedio del $12 \%$. Ventas anuales crecieron en $30 \%$ de las cuales un $90 \%$ corresponde a terceros.

2006: La rentabilidad llegó a un 39,5\%, lo que se compara favorablemente con el alza del índice bursátil de las 40 acciones más transadas IPSA que rentó un 38,9\%. El patrimonio es un 10,8\% superior al año anterior, por buenos resultados y por la constante política de retener la mayor parte de las utilidades para potenciar el crecimiento de la compañía.

2007: Los resultados muestran un importante crecimiento en relación al año anterior, el mayor de la historia. La rentabilidad anual anotó una fuerte alza, llegando a un $82,2 \%$ lo que se compara favorablemente con el alza del índice bursátil de las 40 acciones más transadas IPSA que rentó un 13,5\%.

2008: Se comenzó a sentir los efectos de la Crisis Subprime, a través de la baja en el valor bursátil de las acciones. Cabe señalar el incremento del $43 \%$ respecto al año anterior de los Ingresos de Explotación de la compañía. Los ingresos operacionales del año 2008 fueron positivos, mostrando un incremento de un $43 \%$.

2009: El Resultado Fuera de la Explotación alcanzó a M\$3.091 los que se vieron 
afectados positivamente por la consolidación de resultados en los consorcios en que participa.

2010: El año 2010 estuvo marcado por el terremoto, al cual la empresa puso en marcha planes de contingencia que permitieron rápidamente volver al normal desarrollo de sus obras. Trayendo grandes resultados tras los numerosos contratos de reconstrucción que suscribió, lo que se aprecia en una expansión de las ventas del $15 \%$.

2011: Las perspectivas de la economía mundial no son del todo claras, si bien el país estaba en una buena posición para enfrentar esta incertidumbre, el gran grado de riesgo en la economía puso alerta a inversionistas, provocando inestabilidad de las acciones.

2012: El resultado alcanzó a \$25.616 millones después de impuestos, eso producto de la venta del $100 \%$ de las acciones de dos concesionarias lo que produjo una ganancia extraordinaria de operaciones discontinuas de $\$ 9.176$ millones.

2013: Besalco Construcciones presentó una pérdida de $\$ 11.092$ millones, el que se explica por proyectos de la filial, que presenta en total pérdidas por $\$ 10.374$ millones, explicado por el aumento del costo de la mano de obra.

2014: El resultado de la compañía arroja pérdidas por $\mathrm{M} \$ 11.848 .800$. Por primera vez desde que Besalco S.A. cotiza sus acciones en una bolsa de valores (1995). Explicado por desvíos presupuestarios en algunas obras específicas, principalmente el Mall de Copiapó y los hospitales de Copiapó y Talca, producto del aumento del costo de mano de obra y de interferencias de proyecto por parte de los mandantes. 


\section{CMPC}

Gráfico 5: Comportamiento de las acciones de CMPC.

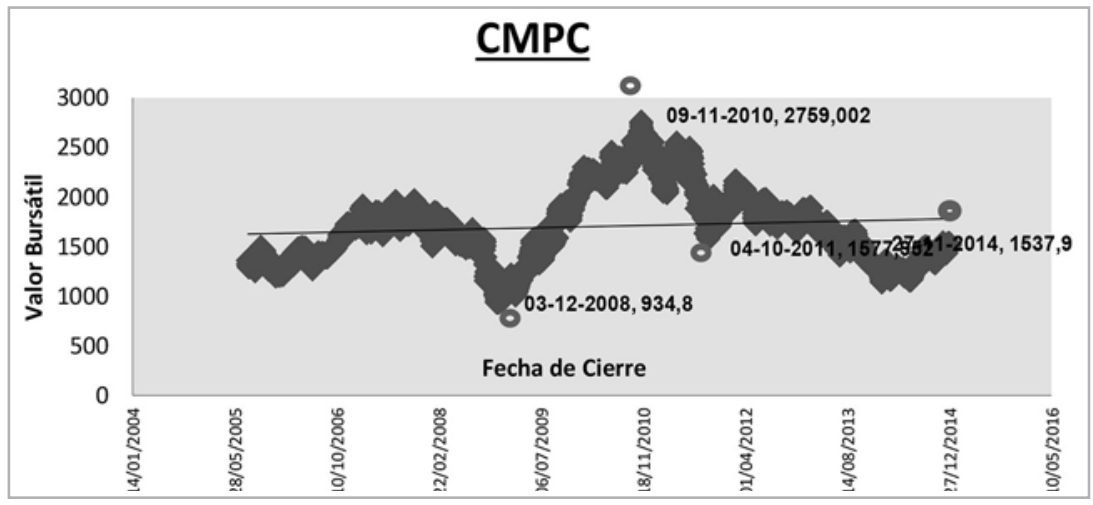

Fuente: Elaboración propia en base a la información proporcionada por la Bolsa de Comercio de Santiago.

2005: La empresa alcanzó una utilidad de \$122.987 millones, cifra 29\% inferior a la del año anterior. Este resultado fue como consecuencia de factores que afectaron muy negativamente los costos. Los precios de explotación de algunos papeles tuvieron alzas moderadas a lo largo del año. El positivo desempeño de la economía chilena (consumo), impulsó el crecimiento de las ventas en el mercado doméstico.

2006: La expansión de la economía internacional fue positiva para la demanda de sus productos. Sin embargo, altos precios de ciertos commodities como el petróleo, energía y el cobre, influyó en la apreciación del tipo de cambio en Chile, con el consiguiente deterioro de los márgenes en los negocios de exportación de CMPC.

2007: La aguda contracción del mercado de la construcción en Estados Unidos, debido a la Inflación Inmobiliaria, produjo una reducción de la demanda de productos para este sector, afectando los precios de manufacturas que se venden en dicho mercado.

2008: La crisis Subprime redujo los márgenes de rentabilidad. El negocio de celulosa experimentó reducción en la demanda y caída en los precios de mercado. En el verano se vieron afectadas 206 hectáreas de bosques productivos por incendios forestales.

2009: Durante el año las ventas consolidadas fueron un $4,5 \%$ menos que el año anterior, resultado de una fuerte reducción de precios, costos en los productos y los efectos de la evolución del tipo de cambio en su impacto sobre la deuda 
financiera.

2010: El terremoto provocó que Plantas industriales debieran paralizar, lográndose la recuperación total de las operaciones. A pesar de eso la compañía tuvo mejorías en su rentabilidad, por la adquisición de nuevos proyectos y maquinas más modernas. La utilidad del ejercicio ascendió a 139\% más que lo registrado el 2009. Estos resultados son la consecuencia de precios de la celulosa.

2011: CMPC enfrentó una caída en los precios de la celulosa y una sostenida presión en los gastos de operación relacionados a mayores precios de insumos, gastos asociados a proyectos en desarrollo y costos en monedas locales.

2012: La economía mundial mostró un menor crecimiento que en el año anterior, pero aun así continuaron los efectos de inestabilidad debido a la fuerte Crisis en Europa.

2013: Las ventas consolidadas representaron un 5\% de crecimiento frente al año anterior. En noviembre la planta Papeles Río Vergara detuvo su fabricación de papel por el aumento del costo de producción derivado del alto precio de la energía eléctrica.

2014: La economía se desaceleró más de lo estimado, debido a factores externos e internos. Entre los primeros está la Desaceleración de China. En el ámbito forestal, se caracterizó por un aumento de la conflictividad en algunas zonas con vecindad de comunidades Mapuche y donde Forestal Mininco tiene parte de su patrimonio.

\section{SQM}

Gráfico 6: Comportamiento de las acciones de SQM.

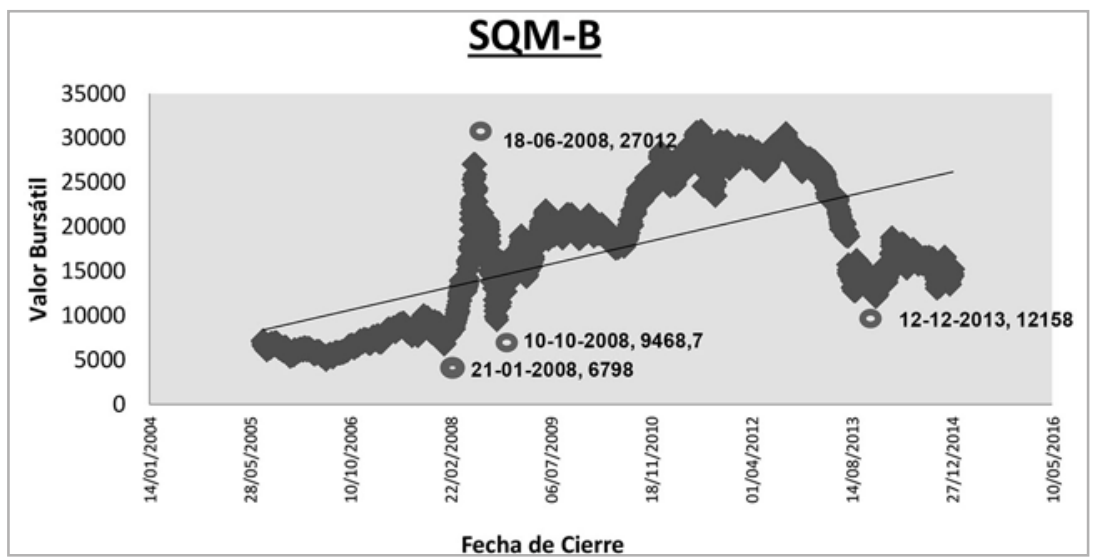

Fuente: Elaboración propia en base a la información proporcionada por la Bolsa de Comercio de Santiago. 
2005: Experimentó un crecimiento del 52,9\% en sus resultados por la recuperación de los precios de los productos de la Compañía, junto con el aumento de la demanda registrada en los negocios: Nutrientes Vegetales de Especialidad, Yodo y Litio. Concretó la adquisición del negocio del yodo y derivados de yodo de la empresa holandesa DSM.

2006: Aumentaron tanto los ingresos como las utilidades, los mayores resultados se explican por el aumento de los precios en los mercados de las tres principales líneas de negocio y mayores volúmenes de venta en los negocios de yodo y litio.

2007: Las utilidades fueron un 3,6\% inferior a la utilidad del año anterior. Los Ingresos obtenidos alcanzaron un $31 \%$ más a los registrados el año anterior. Bajo el precio del dólar, lo que desfavorece al sector exportador y la alta tasa de inflación, lo cual influyó directamente en los costos de las empresas.

2008: El factor más relevante tuvo que ver con el aumento de la demanda de fertilizantes y a biocombustibles. En el segundo semestre disminuyó la demanda mundial de fertilizantes, cuando esta comenzó a corregirse debido a la caída de los commodities.

2009: Corrección de los precios a la baja. La reactivación fue más lenta de lo que había estimado, teniendo sólo una leve mejora hacia fines de año.

2010: La utilidad neta de la controladora alcanza una variación positiva de 13,36\% con respecto al mismo periodo del año anterior. Los ingresos presentaron una baja del 6,00\% respecto al periodo anterior. El segundo semestre del año 2010 se vislumbró una recuperación significativa en los precios.

2011: La recuperación asociada al alza del precio de los granos, se observó también durante este período, sin embargo, producto de la incertidumbre provocada en parte por la crisis financiera, los precios de los commodities entraron en un período de inestabilidad.

2012: Las tendencias de precios se mantuvieron con una tendencia general a la baja, lo cual se reflejó en el mercado local. El tipo de cambio, tuvo un comportamiento similar al del año anterior con un valor promedio bajo la barrera de los quinientos pesos, lo cual afectó algunos sectores del mercado y también algunas líneas de gastos de la empresa. 
2013: La utilidad neta de la controladora tuvo variación positiva de $21,40 \%$ con respecto al mismo período del año anterior. La entidad lanzó un número importante de nuevos productos y nuevos formatos de empaque, además de ampliar segmentos.

2014: La utilidad neta de la controladora aumentó en un 15,19\%. Durante el mismo año surgió la consolidación de Agrorama, empresa distribuidora de agro-insumos.

\section{Aplicación y Análisis prueba de Kolmogorov-Smirnov para Sector Materiales} Básicos, Industriales y Construcción.

Cuadro 6: Prueba de Kolmogorov-Smirnov del Sector Materiales Básicos, Industriales y Construcción

Prueba de Kolmogorov-Smirnov para una muestra

\begin{tabular}{|ll|r|r|r|}
\hline & & BESALCO & \multicolumn{1}{|c|}{ CMPC } & SQM \\
\hline $\mathrm{N}$ & & 2137 & 2137 & 2137 \\
Parámetros & Media & 500,390 & 1727,803 & 17633,904 \\
normales $^{\mathrm{a}, \mathrm{b}}$ & Desviación & 281,363 & 373,058 & 7984,062 \\
& estándar &, 121 &, 064 &, 119 \\
Máximas & Absoluta &, 121 &, 064 &, 119 \\
diferencias & Positivo &,- 098 &,- 048 &,- 100 \\
extremas & Negativo &, 121 &, 064 &, 119 \\
&, $086^{\mathrm{c}}$ &, $098^{\mathrm{c}}$ &, $071^{\mathrm{c}}$ \\
\hline
\end{tabular}

Fuente: Elaboración propia en base a la información proporcionada por la Bolsa de Comercio de Santiago.

Puesto que el valor del nivel crítico (Sig. Asintótica bilateral) es mayor a los grados de significancia $(0,05)$, se acepta la hipótesis de normalidad para el Sector Materiales básicos, industria y construcción y se concluye que la muestra se ajusta a una distribución normal donde la prueba más acorde a esta distribución es la de Pearson. 


\section{Aplicación y Análisis prueba de Pearson para Sector Materiales básicos, Industriales y Construcción.}

Cuadro 7: Prueba Correlación Pearson del Sector Materiales Básicos, Industriales y Construcción.

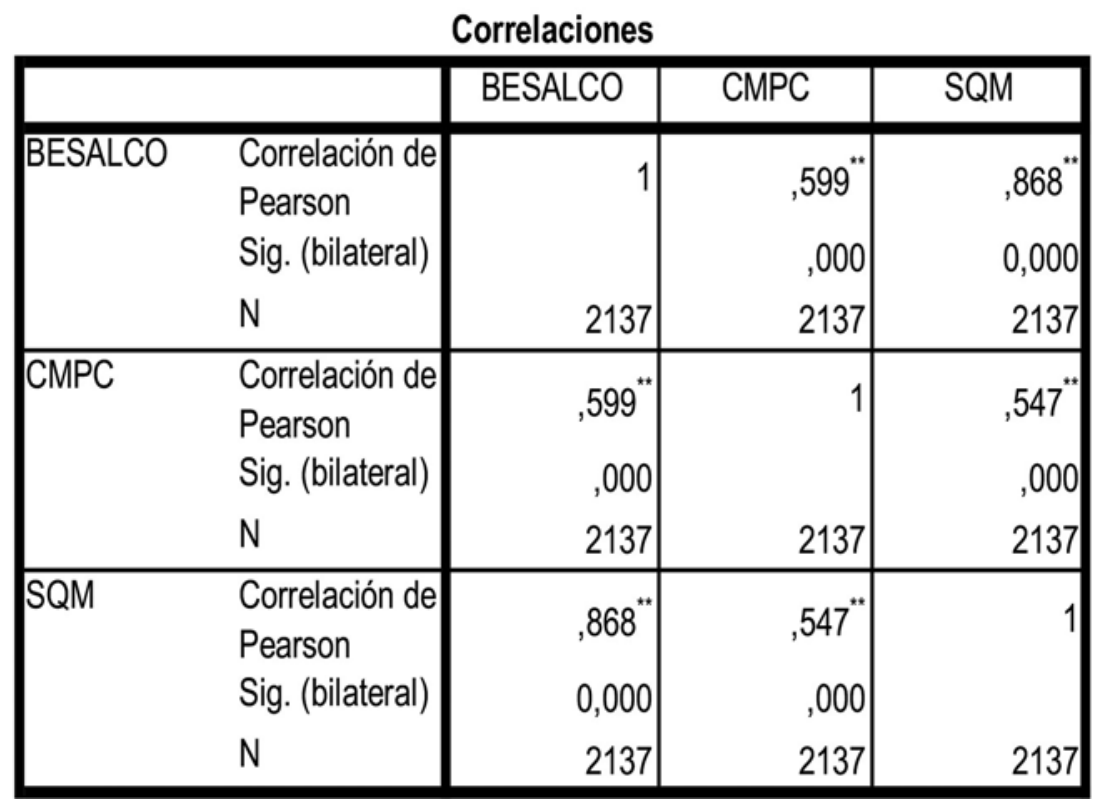

Fuente: Elaboración propia en base a la información proporcionada por la Bolsa de Comercio de Santiago.

Al comparar BESALCO con CMPC, se obtiene un índice de correlación de 0,599, el cual indica que existe correlación entre el valor de las acciones. Al comparar SQM con BESALCO, se obtiene un índice de correlación de 0,868, el cual indica que existe correlación entre el valor de las acciones. Y por último al comparar CMPC con SQM, se obtiene un índice de correlación de 0,547, el cual indica que existe correlación entre el valor de las acciones. 


\section{Análisis del Sector Bienes de Consumo}

Tercer Sector Económico: empresas Embonor-B, Concha y Toro y CCU (20052014).

\section{EMBONOR}

Gráfico 7: Comportamiento de las acciones de EMBONOR.

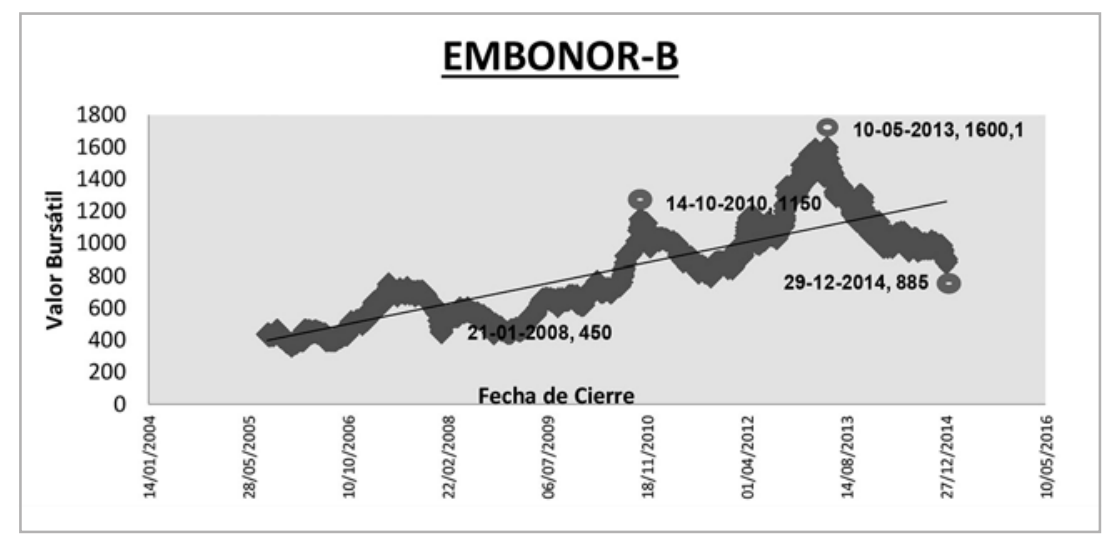

Fuente: Elaboración propia en base a la información proporcionada por la Bolsa de Comercio de Santiago.

2005: Alcanzó una utilidad neta record de \$ 17.202 millones.

2006: Junta general extraordinaria de accionistas de Inversora Los Andes S.A., propone disminuir el capital de la sociedad a US\$ 6.000 .000 , se hizo efectiva en el mes de julio.

2007: Se diversificaron productos para satisfacer necesidades de los distintos grupos de consumidores, destaca Coca-Cola Zero, también lanzaron nuevos productos como son Nestea, Andina Forte y Andina 100\% Jugo. Adquirió la marca de aguas Benedictino.

2008: La entidad comenzó a sentir los efectos de la Burbuja Inmobiliaria y Crisis Financiera Subprime, se vio expuesta a alzas de precios de insumos y a efectos del alza del petróleo que afectó el costo de la energía. Fueron afectados por un alza en el tipo de cambio en Chile que impactó negativamente los costos de insumos.

2009: La entidad amplió la oferta de productos en categorías de aguas y jugos.

2010: El terremoto provocó daño en instalaciones y plantas de la compañía, destrucción de botellas, cajas plásticas y productos terminados, en bodegas y sucursales; cubiertos con los respectivos seguros. Existió un incremento en 
costo de materia prima, mayor costo laboral y efecto negativo de la conversión de resultado por variación del tipo de cambio.

2011: Los resultados de la Compañía se vieron afectados por presiones de costos en materias primas. Se continuó aplicando el alza en el precio del concentrado. Asimismo, el costo de mano de obra fue afectado por el IPC que alcanzó un 4,4\%. Por otra parte, el alza del petróleo elevó los costos de transporte, distribución y energía.

2012: El volumen de ventas creció un 7,3\% respecto del año anterior y el Resultado Operacional a un $15 \%$ más alto que el año anterior. La utilidad neta se incrementó $3,6 \%$. La operación de la entidad se caracterizó por un fortalecimiento del portafolio de bebidas burbujeantes, mediante el lanzamiento de nuevos productos.

2013: Existió un crecimiento sostenido del valor bursátil de las acciones de Embonor-b fortaleciendo el portafolio de marcas y empaques mediante nuevos lanzamientos e innovaciones. Desde mayo comienza a declinar el valor de las acciones.

2014: El Resultado Operacional refleja una disminución de 2,1\% respecto del año anterior, debido al alza en el costo de la mano de obra; fletes de distribución; y por un incremento en la depreciación, consecuencia de la mayor inversión en activos fijos en los últimos años por parte de la entidad.

\section{CONCHA y TORO}

Gráfico 8: Comportamiento de las acciones

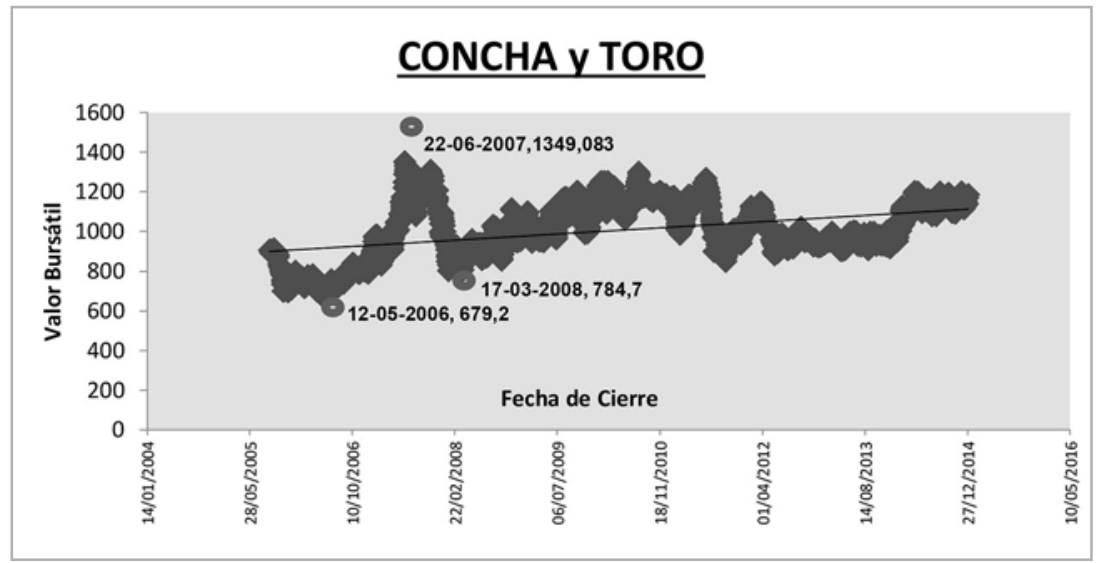

Fuente: Elaboración propia en base a la información proporcionada por la Bolsa de Comercio de Santiago. 
2005: Evolución desfavorable del tipo de cambio ha afectado a la industria, se sumó una significativa alza en los precios de las uvas de la vendimia. Esta caída se explica, por la fuerte apreciación del peso con respecto a las monedas extranjeras en las cuales la Compañía realiza ventas al exterior: dólar norteamericano, euro y libra esterlina.

2006: La fuerte baja experimentada por el tipo de cambio, unida a un escenario externo (sobreoferta de vinos), afectaron la rentabilidad de la industria. Una caída en el consumo del segmento de vinos masivos en beneficio del sustituto, la cerveza. La Compañía mostró un desempeño superior al de la industria nacional al alcanzar un crecimiento de 4,3\% en volumen, sin embargo, la caída de precios llevó a una menor facturación.

2007: Se aprecia un crecimiento producto de la estrategia de negocios, lo que permitió que la compañía creciera por sobre los resultados de la industria. La utilidad del año alcanzó el doble de la cifra obtenida por la entidad en el 2006.

2008: La primera mitad del año se caracterizó por un tipo de cambio extremadamente desfavorable. En tanto, durante la segunda mitad del año hubo mejores condiciones de tipo de cambio, ello, sin embargo, en el contexto de una crisis financiera y económica.

2009: A pesar de que en el 2009 la industria vitivinícola fue fuertemente impactada por la crisis financiera y una desaceleración, tuvo variaciones estables.

2010: Se logró nuevamente variaciones estables. Tras el terremoto, se vio afectada con pérdidas de vino y daños en sus instalaciones. Sin embargo, en un breve periodo la compañía pudo ordenarse y reiniciar sus operaciones. La empresa contaba con pólizas de seguros de todo riesgo, contra terremotos y para la totalidad de sus activos.

2011: Se desenvolvió en un escenario internacional difícil, a lo que se sumó el desafío impuesto por la apreciación del peso chileno, la volatilidad del tipo de cambio, alzas de la materia prima y la incertidumbre económica en el mercado pese al complejo marco general, los resultados alcanzados por la compañía en el periodo fueron positivos.

2012: A la desaceleración China y los efectos de la Crisis Eurozona, se sumaron alzas importantes en el precio de principales materias primas y un tipo de cambio 
desfavorable.

2013: Tuvo precios constantes en comparación a periodos anteriores, estabilidad en la estructura productiva y comercial la cual tiene foco el segmento Premium. También se puede señalar que hubo un avance, por el incremento de las ventas externas, inversiones en construcción de nuevas marcas, y el efecto de un tipo de cambio más favorable.

2014: El enfoque de innovación logró responder a nuevos desafíos de la industria y retomar un buen ritmo de crecimiento, alcanzando durante el año aumento en ventas y utilidades.

\section{CCU}

Gráfico 9: Comportamiento de las acciones de CCU.

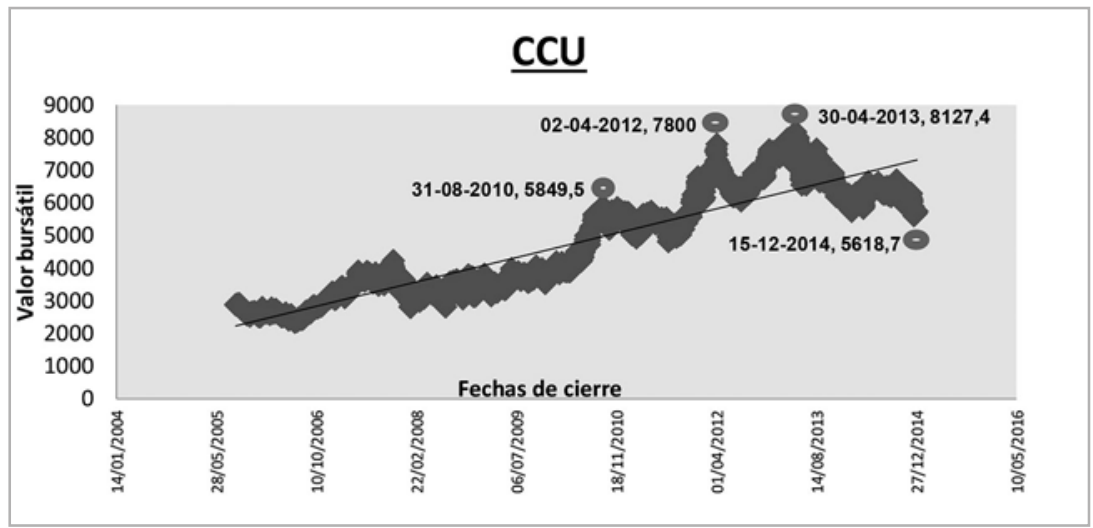

Fuente: Elaboración propia en base a la información proporcionada por la Bolsa de Comercio de Santiago.

2005: Los ingresos por venta tuvieron un incremento de 11,4\%. El resultado operacional aumento 9,4\%, explicado por los mayores ingresos por ventas.

2006: Todos los segmentos del negocio mejoraron sus resultados, con excepción de vinos. La rentabilidad del segmento vinos continúo afectada por la apreciación del peso chileno, además de una disminución de las ventas en el mercado doméstico.

2007: Todos los segmentos de negocios en Chile mejoraron sus resultados durante el año. El segmento vinos tuvo un año muy positivo, mejorando su resultado operacional, por menores costos de la materia prima, incremento en el precio promedio de exportación en dólares y mayores volúmenes en Chile en los 
mercados doméstico.

2008: En un ambiente de presiones de costo, tanto por mayores precios de materias primas como por la depreciación del peso chileno respecto del dólar y el euro, todos los segmentos tuvieron una mejoría en su EBITDA respecto del año anterior, con la salvedad del segmento cervezas el cual enfrentó grandes desafíos por presiones de costos.

2009: El Plan Aumento de Consumo de Cerveza enfrentó un consumo deprimido por la situación económica general y por el nivel de desempleo en particular.

2010: Cervezas en Chile fue uno de los segmentos más afectados por el terremoto, las dificultades en la continuidad del abastecimiento se manifestaron en una caída de volúmenes. El segmento vinos fue otro que también se vio afectado por el terremoto.

2011: Resultados satisfactorios a pesar de enfrentarse a un escenario desfavorable en materia de costos y gastos, pues recién iniciado el año comenzaron a subir los precios de las materias primas, petróleo y electricidad a un ritmo acelerado. Ante este escenario pusieron en marcha un plan de contingencia, tanto en materia de precios, gastos, inversiones, innovaciones y nuevos proyectos.

2012: El valor bursátil de las acciones aumentó a pesar de las presiones de costos, del ambiente de mayor competitividad que se enfrentaron y al impacto en que provocó en las categorías alcohólicas la modificación a la ley de tránsito en materia de conducción a partir de marzo 2012. La Compañía materializó la adquisición de nuevos negocios.

2013: CCU tuvo un aumento de capital. Los recursos obtenidos del aumento de capital se utilizaron para financiar un plan de expansión, que contempla el crecimiento orgánico e inorgánico de la Compañía en Chile y la Región.

2014: La desaceleración económica, la devaluación de las monedas locales, la inflación en los costos y las alzas de impuestos, tuvieron un impacto que se reflejó en resultados. 


\section{Aplicación y Análisis prueba de Kolmogorov-Smirnov para Sector Bienes de Consumo.}

Cuadro 8: Prueba de Kolmogorov-Smirnov del Sector Bienes de Consumo.

\section{Prueba de Kolmogorov-Smirnov para una muestra}

\begin{tabular}{|ll|r|r|r|}
\hline & & EMBONOR-B & CONCHAYTORO & \multicolumn{1}{c|}{ CCU } \\
\hline$N$ & 2137 & 2137 & 2137 \\
Parámetros & Media & 500,390 & 1727,803 & 17633,904 \\
normales ${ }^{\mathrm{a}, \mathrm{b}}$ & Desviación & 281,363 & 373,058 & 7984,062 \\
& estándar &, 121 &, 064 &, 119 \\
Máximas & Absoluta &, 121 &, 064 &, 119 \\
diferencias & Positivo &,- 098 &,- 048 &,- 100 \\
extremas & Negativo &, 121 &, 064 &, 119 \\
& Estadistico de prueba &, $176^{\mathrm{c}}$ &, $132^{\mathrm{c}}$ &, $154^{\mathrm{c}}$ \\
\hline
\end{tabular}

Fuente: Elaboración propia en base a la información proporcionada por la Bolsa de Comercio de Santiago.

Puesto que el valor del nivel crítico (Sig. Asintótica bilateral) es mayor a los grados de significancia $(0,05)$, se acepta la hipótesis de normalidad para el Sector Bienes de Consumo y se concluye que la muestra se ajusta a una distribución normal donde la prueba más acorde a esta distribución es la de Pearson.

\section{Aplicación y Análisis prueba de Pearson para Sector Bienes de Consumo.} Cuadro 9: Prueba Correlación Pearson del Sector Bienes de Consumo.

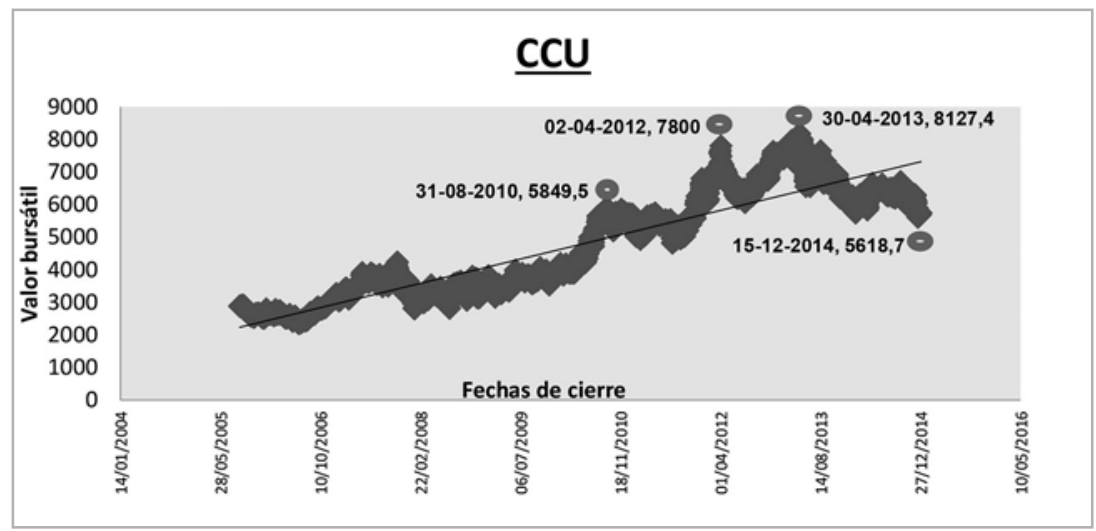

Fuente: Elaboración propia en base a la información proporcionada por la Bolsa de Comercio de Santiago.

Al comparar EMBONOR con CONCHA y TORO, se obtiene un índice de correlación de 0,201, el cual indica que no existe correlación entre el valor de las acciones. Al comparar CONCHA y TORO con CCU, se obtiene un índice de correlación de 0,269, 
el cual indica que no existe correlación entre el valor de las acciones. Y por último al comparar CCU con EMBONOR, se obtiene un índice de correlación de 0,947, el cual indica que existe correlación entre el valor de las acciones.

\section{Análisis del Sector Servicios de Consumo}

Cuarto Sector Económico: empresas Cencosud, Ripley y Falabella (2005-2014)

\section{CENCOSUD}

Gráfico 10: Comportamiento de las acciones de CENCOSUD.

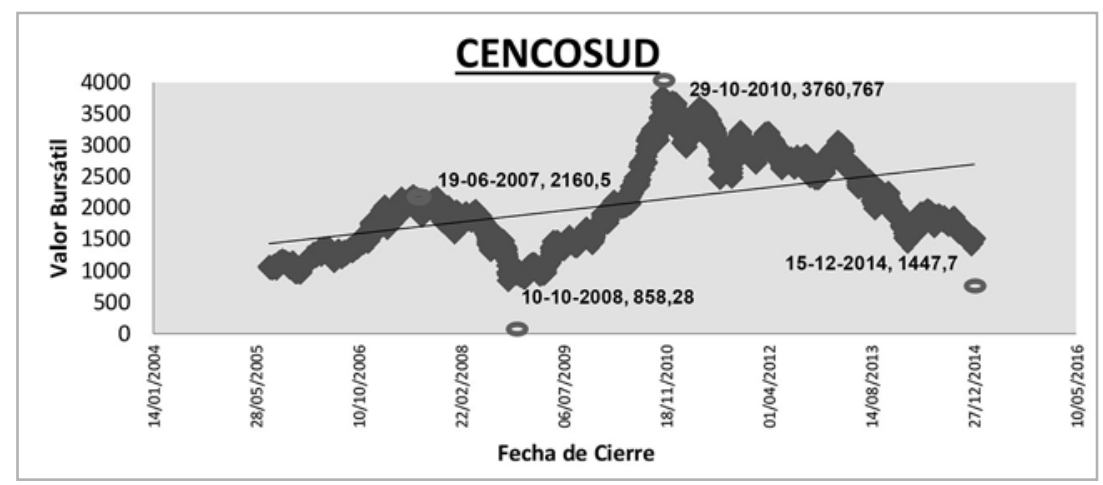

Fuente: Elaboración propia en base a la información proporcionada por la Bolsa de Comercio de Santiago.

2005: La fusión del holding Paris con Cencosud S.A, se produjo a través de un canje de acciones, la desaparición por absorción de la sociedad Empresas Almacenes Paris S.A. Esto a su vez significó la entrada de la acción Cencosud al IPSA, alcanzando la segunda posición entre las empresas cuyas acciones son más transadas en el mercado chileno.

2006: Continúa con su expansión supermercadista en Chile, con la adquisición de las cadenas Economax, incorporando 16 locales a la compañía. Asimismo, adquirió la cadena de tiendas de ropa Foster/Eurofashion.

2007: Adquirió la supermercadista GBarbosa en el Nordeste de Brasil. Por último firma un acuerdo de compra con el Grupo Wong en Perú. Se colocaron 75.000.000 acciones, con el propósito de financiar en parte el pago del precio acordado.

2008: La Crisis Subprime generó incertidumbre a nivel mundial, afectando el valor accionario entre las cuales se encontraba Cencosud. También existió una caída de las acciones, con la renuncia de gerente general, que desencadeno de inmediato que el mercado accionario comenzara a resentirse provocando la baja cotización. 
2009: La rentabilidad de las operaciones, así como en la generación de caja contribuyó a un impacto positivo, a pesar de la gran incidencia de los efectos de la crisis financiera Subprime, del impacto negativo de las paridades cambiarias y corrección monetaria.

2010: Inserción en Brasil con paso firme: con las adquisiciones de Brettas, Super Familia y Perinila entidad logró posicionarse como el mayor operador de supermercados. La utilidad aumentó $24 \%$ respecto al año anterior. Este aumento de rentabilidad también reflejó el aumento del consumo tras el terremoto de febrero.

2011: Se apreció un buen primer semestre y uno segundo más débil, como consecuencia de un deterioro en las condiciones externas que enfrentó la economía chilena.

2012: Las acciones cayeron más de $6 \%$ en la Bolsa, tras anunciar la compra de Carrefour Colombia por más de US2.600 millones. La caída de la acción pudo ser un reflejo de la preocupación que habría generado en el mercado, el efecto combinado entre el múltiplo alto de la operación y que la adquisición requerirá un nivel de endeudamiento importante.

2013: La empresa reportó un derrumbe del $78 \%$ en sus utilidades del segundo trimestre, a 7.976 millones de pesos, ante mayores costos financieros y efectos cambiarios. Las acciones de Cencosud acumulaban una caída que superaba el $20 \%$.

2014: La utilidad anual, fue de $35,7 \%$ menor a 2013 , lo que se explica por una combinación de factores como, mayores gastos financieros, ajuste de monedas y desaceleración económica en algunos mercados en los que operaba la compañía. 


\section{RIPLEY}

Gráfico 11: Comportamiento de las acciones de RIPLEY.

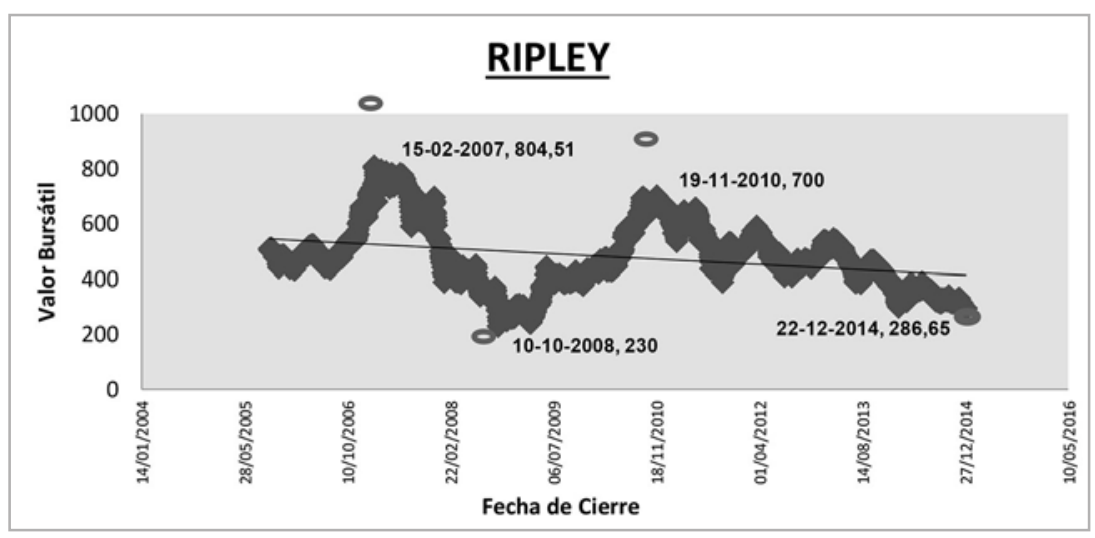

Fuente: Elaboración propia en base a la información proporcionada por la Bolsa de Comercio de Santiago.

2005: Concretó la inauguración de dos nuevas sucursales. Las ventas a sucursales iguales aumento en un 5,3\%, respecto al 2004 y se comenzó la introducción de marcas.

2006: Marcado por la inauguración de tres sucursales y por los lanzamientos de grandes marcas. Respecto al resultado operacional aumentó $18 \%$ y la utilidad neta creció $133 \%$.

2007: La economía chilena se vio afectada por la incertidumbre tras la Burbuja Inmobiliaria. Si bien la inflación registrada incidió negativamente en el crecimiento de las ventas, el consumo total creció $7,4 \%$ impulsado por el consumo privado.

2008: Como consecuencia de la inestabilidad económica que provocó la Crisis Subprime, el mercado mostró un aumento en los niveles de morosidad, por lo que junto con el incremento de los ingresos financieros se elevó el nivel de provisiones.

2009: Desaceleración en el consumo y un significativo aumento en los niveles de morosidad, observó un positivo cambio de tendencia en consumo, lo que llevó a un incremento de $12,2 \%$ en la venta retail durante el cuarto trimestre del año.

2010: El terremoto incidió en un aumento en los ingresos de retail en un 18,9\%, en línea con la estrategia de la compañía de aumentar el valor de sus marcas y potenciar la relación precio calidad de sus productos en todas las áreas de negocio. 
2011: Tuvo un importante plan de apertura de tiendas, que contemplaba abrir dos nuevas tiendas en Chile y cuatro nuevas tiendas en Perú. En Chile destaca la apertura en el Mall Costanera Center de Santiago. Pero a pesar de esto el valor bursátil de las acciones se ha vio drásticamente disminuido durante el periodo tras la desvaluación del peso chileno.

2012: El valor de las acciones nuevamente se vio afectado por la desaceleración de China. Año de grandes inversiones, con un significativo aumento en las ventas, tanto en tiendas por departamento como en negocio, todo este crecimiento significó un aumento en los costos pre operativos, afectando negativamente los resultados del año.

2013: Uno de los hitos más importantes fue la integración del negocio financiero en Chile bajo Banco Ripley, la que se materializó luego de recibida la aprobación de la Superintendencia de Bancos e Instituciones Financieras. Por otra parte, comenzó también la comercialización de la Tarjeta Ripley MasterCard. Pero las acciones de Ripley siguieron desplomándose tras la incertidumbre en la economía mundial.

2014: El valor de las acciones se vio afectado por la caída de precios del petróleo y de las materias primas y depreciación de sus monedas. En un año marcado por un menor dinamismo económico, aumentos del tipo de cambio y mayor inflación.

\section{FALABELLA}

Gráfico 12: Comportamiento de las acciones de FALABELLA.

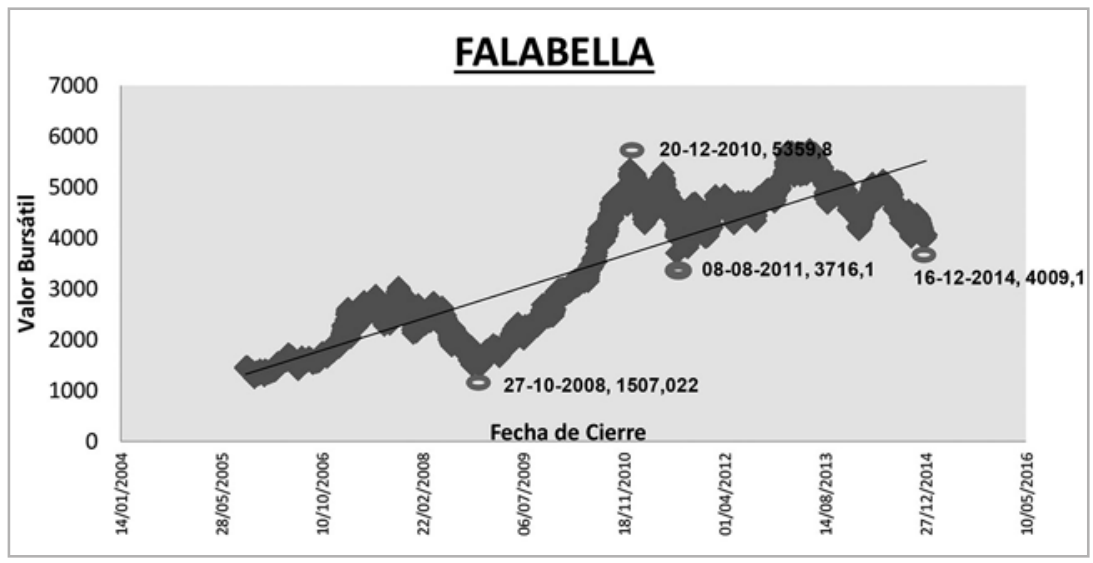

Fuente: Elaboración propia en base a la información proporcionada por la Bolsa de Comercio de Santiago 
2005: Resultados fueron positivos con ingresos por US\$3853 millones, con un crecimiento de $18,6 \%$ en relación a 2004 y utilidades por US\$315 millones, 24\% más.

2006: Utilidad de 20,2\% por un total de USD 371,5 millones, mientras los ingresos consolidados alcanzaron un 15,5\% más que el año anterior.

2007: La Junta de Accionistas aprobó un aumento de capital superior a los USD 1.000 millones, con el objetivo de otorgar mayor flexibilidad a la administración para poder ampliar el plan de inversiones, contar con recursos para potenciales oportunidades de crecimiento.

2008: El año culminó con una profunda crisis económica, experimentó inversiones por sobre los USD 600 millones, producto de la inauguración de 39 tiendas nuevas y 3 malls.

2009: Importante baja en el nivel de consumo y la desaceleración de la construcción, pero con planes y mejoras operacionales la entidad pudo hacer frente a la recesión económica.

2010: Buenos resultados alcanzados a principio del año, producto del aumento de consumo (Homcenter Sodimac), debido a la reconstrucción.

2011: Se vio favorecida por la fuerte demanda de recursos naturales desde China y por un aumento de la demanda interna. Es por eso que Falabella obtuvo positivos resultados.

2012: Ventas alcanzaron los US\$ 12.309 millones, lo que representó un aumento de $15 \%$ en comparación al año anterior. Los resultados se vieron impactados por el aumento de la tasa de impuesto a la renta desde el $18,5 \%$ al $20 \%$. Esta reforma se implementó en septiembre, pero afectó retroactivamente los resultados. Tuvo un impacto negativo por mayores gastos de impuestos diferidos, lo que disminuyó la utilidad.

2013: Tuvo un crecimiento regional, ingresando a Brasil, mediante la adquisición de la cadena Dicico. Permitió alcanzar un incremento de 12,3\% en comparación al año 2012. Desde el segundo semestre se comenzó a ver una disminución en el valor bursátil de las acciones causado por la apreciación del peso chileno versus las monedas extranjera. 
2014: El valor de las acciones se vio afectado por la caída de precios del petróleo y de las materias primas, generando una desaceleración del consumo y depreciación de sus monedas. Fue un año marcado por un menor dinamismo económico, aumentos del tipo de cambio y mayor inflación.

\section{Aplicación y Análisis prueba de Kolmogorov-Smirnov para Sector Servicios de} Consumo.

Cuadro 10: Prueba de Kolmogorov-Smirnov del Sector Servicios de Consumo.

Prueba de Kolmogorov-Smirnov para una muestra

\begin{tabular}{|ll|r|r|r|}
\hline & & CENCOSUD & RIPLEY & FALABELLA \\
\hline N & & 2309 & 2309 & 2309 \\
Parámetros & Media & 2074,932 & 479,400 & 3416,629 \\
normales $^{\mathrm{a}, \mathrm{b}}$ & Desviación & 720,711 & 122,165 & 1360,769 \\
& estándar &, 096 &, 081 &, 150 \\
Máximas & Absoluta &, 096 &, 081 &, 129 \\
diferencias & Positivo &,- 072 &,- 035 &,- 150 \\
extremas & Negativo &, 096 &, 081 &, 150 \\
Estadistico de prueba &, $310^{\mathrm{c}}$ &, $134^{\mathrm{c}}$ &, $426^{\mathrm{c}}$ \\
\hline
\end{tabular}

Fuente: Elaboración propia en base a la información proporcionada por la Bolsa de Comercio de Santiago.

Puesto que el valor del nivel crítico (Sig. Asintótica bilateral) es mayor a los grados de significancia $(0,05)$, se acepta la hipótesis de normalidad para el Sector Servicios de Consumo y se concluye que la muestra se ajusta a una distribución normal donde la prueba más acorde a esta distribución es la de Pearson. 
Aplicación y Análisis prueba de Pearson para Sector Servicios de Consumo.

Cuadro 11: Prueba Correlación Pearson del Sector Servicios de Consumo.

\begin{tabular}{|c|c|c|c|c|}
\hline \multicolumn{5}{|c|}{ Correlaciones } \\
\hline & & CENCOSUD & RIPLEY & FALABELLA \\
\hline \multirow[t]{4}{*}{ CENCOSUD } & Correlación de & 1 & $510^{*}$ & $789^{*}$ \\
\hline & Pearson & 1 & ,012 & , 189 \\
\hline & Sig. (bilateral) & &, 000 & 0,000 \\
\hline & $\mathrm{N}$ & 2309 & 2309 & 2309 \\
\hline \multirow[t]{4}{*}{ RIPLEY } & Correlación de & $510^{* "}$ & 1 & $088^{\circ *}$ \\
\hline & Pearson & & & م, \\
\hline & Sig. (bilateral) &, 000 & &, 000 \\
\hline & $\mathrm{N}$ & 2309 & 2309 & 2309 \\
\hline \multirow[t]{4}{*}{ FALABELLA } & Correlación de & $789^{*}$ & $088^{* *}$ & \\
\hline & Pearson & & & \\
\hline & Sig. (bilateral) & 0,000 &, 000 & \\
\hline & $\mathrm{N}$ & 2309 & 2309 & 2309 \\
\hline
\end{tabular}

Fuente: Elaboración propia en base a la información proporcionada por la Bolsa de Comercio de Santiago.

Al comparar CENCOSUD con RIPLEY, se obtiene un índice de correlación de 0,512, el cual indica que existe correlación entre el valor de las acciones. Al comparar RIPLEY con FALABELLA, se obtiene un índice de correlación de 0,088, el cual indica que no existe correlación entre el valor de las acciones. Y por último al comparar FALABELLA con CENCOSUD, se obtiene un índice de correlación de 0,789 , el cual indica que existe correlación entre el valor de las acciones. 


\section{Análisis del Sector Servicios Financieros e Inmobiliarios}

Quinto Sector Económico: empresas BCl, Habitat y Security (2005-2014)

BCI

Gráfico 13: Comportamiento de las acciones de BCl.

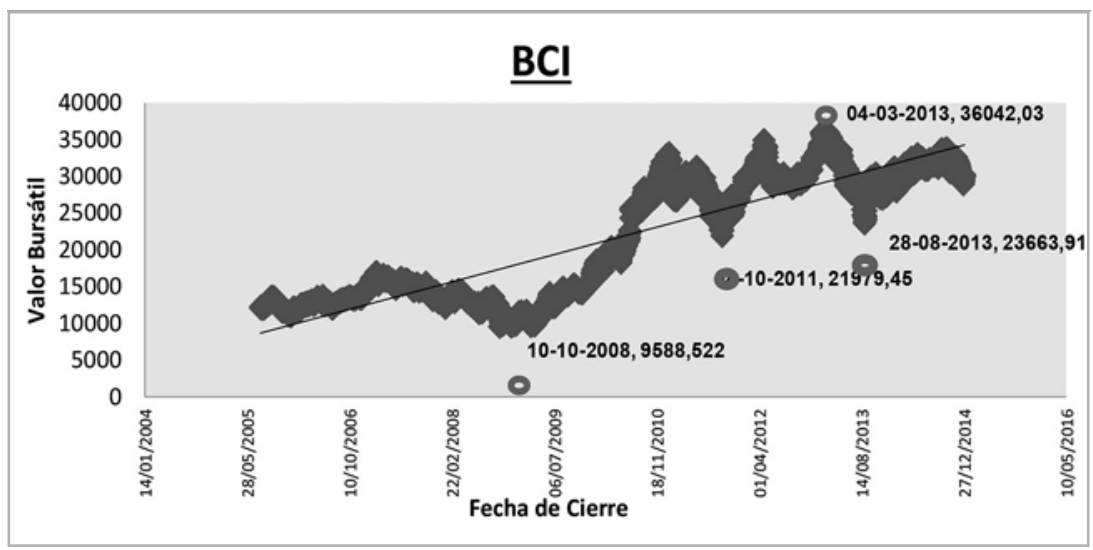

Fuente: Elaboración propia en base a la información proporcionada por la Bolsa de Comercio de Santiago.

2005: La economía chilena exhibió un resultado robusto durante el año 2005. El Banco Central, debido a la persistente tendencia al alza de la inflación, aumentó la tasa de interés de política monetaria.

2006: El crecimiento de la región se habría ubicado en torno al 8,2\%, cifra que representa su mayor tasa de expansión desde 1996. La actividad agregada experimentó una significativa desaceleración. La economía finalizó el año con una expansión de 4,0\%, conforme con la revisión de las cuentas nacionales.

2007: Chile no estuvo ajeno a dificultades de la crisis, resultando con una tasa de inflación más alta que la esperada y un crecimiento más bajo que el proyectado.

2008: La situación se agudizó fuertemente, se produjo una gran crisis financiera, principalmente provocada por la alta falta de liquidez que afectó los más importantes intermediarios financieros del mundo. Chile, encontró una posición de estabilidad económica y de ahorro fiscal, lo que permitió enfrentar los inconvenientes.

2009: Los efectos económicos de la crisis se hicieron sentir con gran fuerza en todo el mundo, los mercados financieros internacionales estuvieron al borde del colapso y la economía de muchos países comenzó a sufrir una grave recesión. En Chile, los efectos se manifestaron en una importante disminución del PIB y en un aumento del desempleo. 
2010: El resultado operacional se elevó, debido a la disminución de ciertos gastos y provisiones de la cartera de créditos y mayores ingresos por márgenes de intereses.

2011: A raíz de los desequilibrios en otros países por políticas fiscales sobreexpansivas y en otros por el excesivo endeudamiento del sector privado, aumentó el costo de financiamiento de los gobiernos, subieron las primas de riesgo, se deterioró la solvencia de los bancos, se elevaron la volatilidad y la incertidumbre en los mercados financieros, se incrementó el desempleo, y se debilitó el crecimiento de la actividad económica.

2012: La utilidad neta alcanzó un nuevo máximo histórico de algo más de \$271 mil millones, superando en $3,8 \%$ la cifra lograda el año anterior. Este aumento contrastó con la baja de 5,4\% de la utilidad del resto del sistema bancario.

2013: El Banco mejoró sus resultados financieros; introdujo importantes reformas en sus estrategias, políticas y procedimientos internos.

2014: Pese a que la banca enfrentó numerosos cambios regulatorios, que constituyeron significativos desafíos y pusieron a prueba su capacidad de adaptación, la utilidad neta aumentó 14,2\%, alcanzando un máximo histórico de casi $\$ 343$ mil millones.

\section{HABITAT}

Gráfico 14: Comportamiento de las acciones de HABITAT.

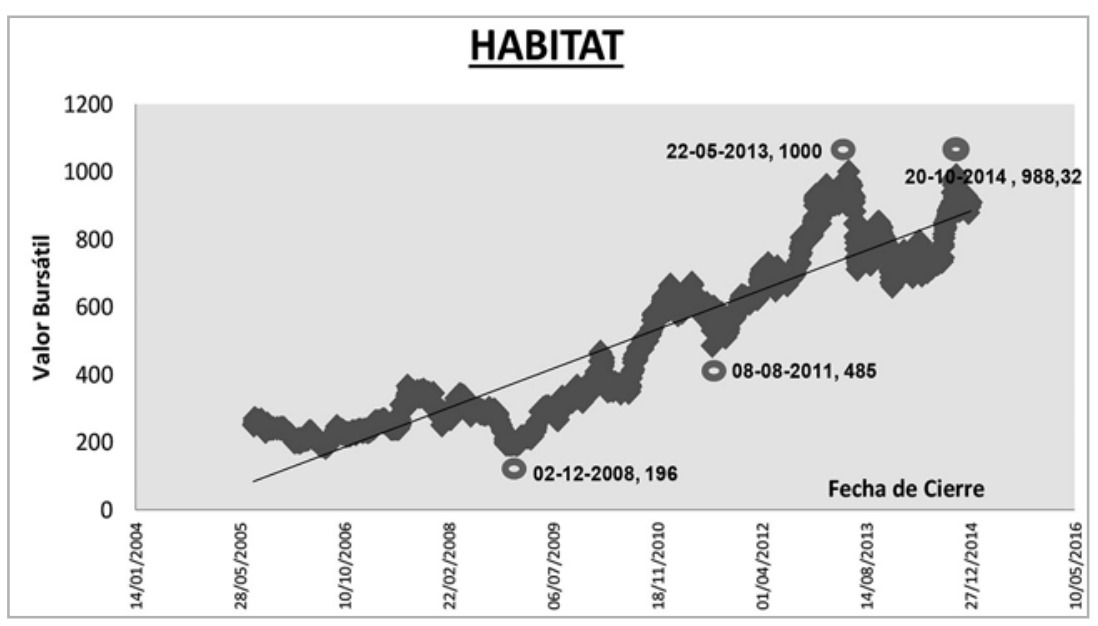

Fuente: Elaboración propia en base a la información proporcionada por la Bolsa de Comercio de Santiago. 
2008: Los efectos de la crisis financiera se dejan ver en los resultados de la gestión de Habitat, cuya utilidad de 4.729 millones de pesos representa una reducción del $89 \%$ si se compara con los 41.668 millones de pesos obtenidos durante el ejercicio anterior.

2009: Ios afiliados a la entidad aumentaron en un 4,1\%; equivalente a casi 85.000 nuevos clientes, alcanzándose 2.132 .388 personas, con un crecimiento de casi un $4,9 \%$ en la renta promedio de los cotizantes del año.

2010: Cambio en la propiedad accionaria de AFP Habitat, el que junto con devolver a la Cámara Chilena de la Construcción el carácter de principal accionista y controlador de la sociedad, permitió el ingreso de un número importante de accionistas minoritarios y una mayor visibilidad de la empresa en el mercado.

2011: Alta incertidumbre financiera en los mercados, impactó negativamente en la rentabilidad de los fondos administrados por las AFP, y por un fuerte deterioro de la confianza pública en estas instituciones, como consecuencia del caso La Polar.

2012: El resultado neto de la compañía aumentó un 21\% en comparación con el periodo anterior, asociado al aumento de los resultados de la inversión del Encaje, dada la positiva evolución que mostró la rentabilidad de los Fondos de Pensiones durante el año.

2013: Durante el año 2013 el resultado neto de la compañía aumentó un 6,6\% en comparación con el periodo anterior, situándose en $\$ 79.473$ millones. Esta variación obedece principalmente a un incremento en el nivel de ingresos de la compañía, también en el manejo acotado de los gastos operacionales y control de inversiones.

2014: Los resultados tuvieron un alza de $18,9 \%$ con respecto al período anterior. La buena rentabilidad de los fondos de pensiones produjo que la utilidad del encaje llegara a $\$ 32.089$ millones, comparada con los $\$ 14.649$ millones obtenidos en el año 2013. 


\section{SECURITY}

Gráfico 15: Comportamiento de las acciones de SECURITY.

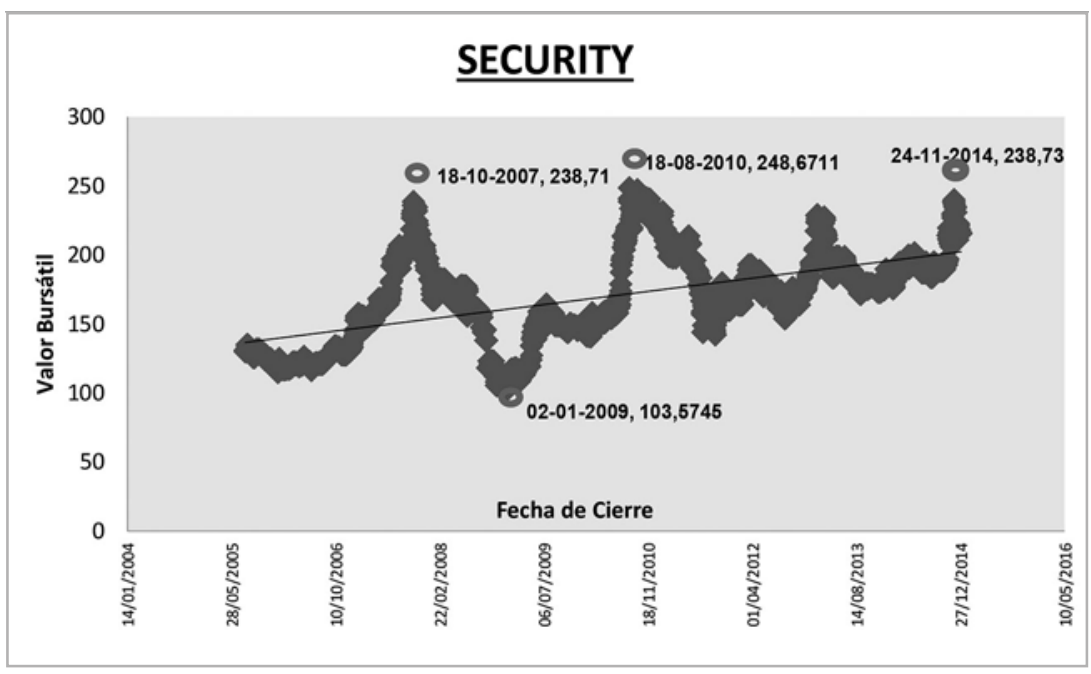

Fuente: Elaboración propia en base a la información proporcionada por la Bolsa de Comercio de Santiago.

2005: Se consolidaron nuevos negocios emprendidos el 2004. Esto se refleja en los resultados de Grupo Security, registrando un notable aumento real, de 25,8\%, respecto del 2004. La rentabilidad alcanzó a 13,1\% del capital y reservas.

2006: Los resultados crecieron, mostrando la rentabilidad con menor volatilidad entre los bancos que operan en la plaza. Los resultados de Banco Security y sus filiales alcanzaron los $\$ 20.498$ millones, con una rentabilidad de $15,5 \%$ sobre el capital y reservas.

2007: A diciembre de 2007, la utilidad del banco y sus filiales llegó a $\$ 27.250$ millones, lograron una rentabilidad de $19,5 \%$ sobre el capital y reservas.

2008: Dicho año será recordado como uno de los más turbulentos de la historia económica mundial, se registraron profundas caídas en las bolsas mundiales, que dieron paso a una alta volatilidad de los mercados.

2009: El segundo semestre estuvo marcado por una incipiente reactivación local y global de la economía. De esta forma, Banco Security y sus filiales, Valores Security Corredores de Bolsa y Administradora General de Fondos Security, sumaron utilidades por $\$ 23.040$ millones, lo cual representa un alza de $64 \%$ con respecto al período anterior. 
2010: Banco Security y sus filiales, sumaron utilidades $46 \%$ más con respecto al periodo anterior. Esto se explica, por el buen desempeño del negocio financiero, la rentabilización de las carteras comerciales, y un riguroso monitoreo de los riesgos y costos, además del impacto de mayor inflación producto de los cambios normativos IFRS.

2011: El inestable entorno económico internacional, influido por los problemas de la deuda soberana europea y la situación económica de Estados Unidos, configuraron un escenario extremadamente complejo.

2012: Banco Security y sus filiales tuvieron un buen desempeño, las utilidades del Banco y sus filiales alcanzaron los M\$35.229, lo cual representa un crecimiento de 0,6\% respecto al año anterior y una rentabilidad de $12,4 \%$ sobre patrimonio.

2013: Concretó un aumento de capital por $M \$ 30.000$ en Banco Security, correspondiente a la primera etapa de un proceso de capitalización por M\$75.000

2014: Fue un año en que Grupo Security logró consolidar sus proyectos, ser reconocido por el mercado y crecer, cerrando el ejercicio con utilidades por $\$ 61.010$ millones, 22,4\% por sobre las obtenidas en el año anterior.

\section{Aplicación y Análisis prueba de Kolmogorov-Smirnov para Sector Servicios Financieros e Inmobiliarios. \\ Cuadro 12: Prueba de Kolmogorov-Smirnov del Sector Servicios Financieros e Inmobiliarios.}

\section{Prueba de Kolmogorov-Smirnov para una muestra}

\begin{tabular}{|ll|r|r|r|}
\hline & & \multicolumn{1}{|c|}{$\mathrm{BCl}$} & HABITAT & SECURITY \\
\hline $\mathrm{N}$ & 2053 & 2309 & 2309 \\
Parámetros & Media & 23558,710 & 505,013 & 864,038 \\
normales $^{\mathrm{a}, \mathrm{b}}$ & Desviación & 8093,539 & 227,297 & 1629,486 \\
& estándar &, 185 &, 160 &, 495 \\
Máximas & Absoluta &, 158 &, 160 &, 495 \\
diferencias & Positivo &,- 185 &,- 082 &,- 320 \\
extremas & Negativo &, 185 &, 160 &, 495 \\
&, $241^{\mathrm{C}}$ &, $198^{\mathrm{C}}$ &, $165^{\mathrm{c}}$ \\
\hline
\end{tabular}

Fuente: Elaboración propia en base a la información proporcionada por la Bolsa de Comercio de Santiago. 
Puesto que el valor del nivel crítico (Sig. Asintótica bilateral) es mayor a los grados de significancia $(0,05)$, se acepta la hipótesis de normalidad para el Sector Servicios financieros e inmobiliarios y se concluye que la muestra se ajusta a una distribución normal donde la prueba más acorde a esta distribución es la de Pearson.

\section{Aplicación y Análisis prueba de Pearson para Sector Servicios Financieros e Inmobiliarios.}

Cuadro 13: Prueba Correlación Pearson del Sector Servicios Financieros e Inmobiliarios.

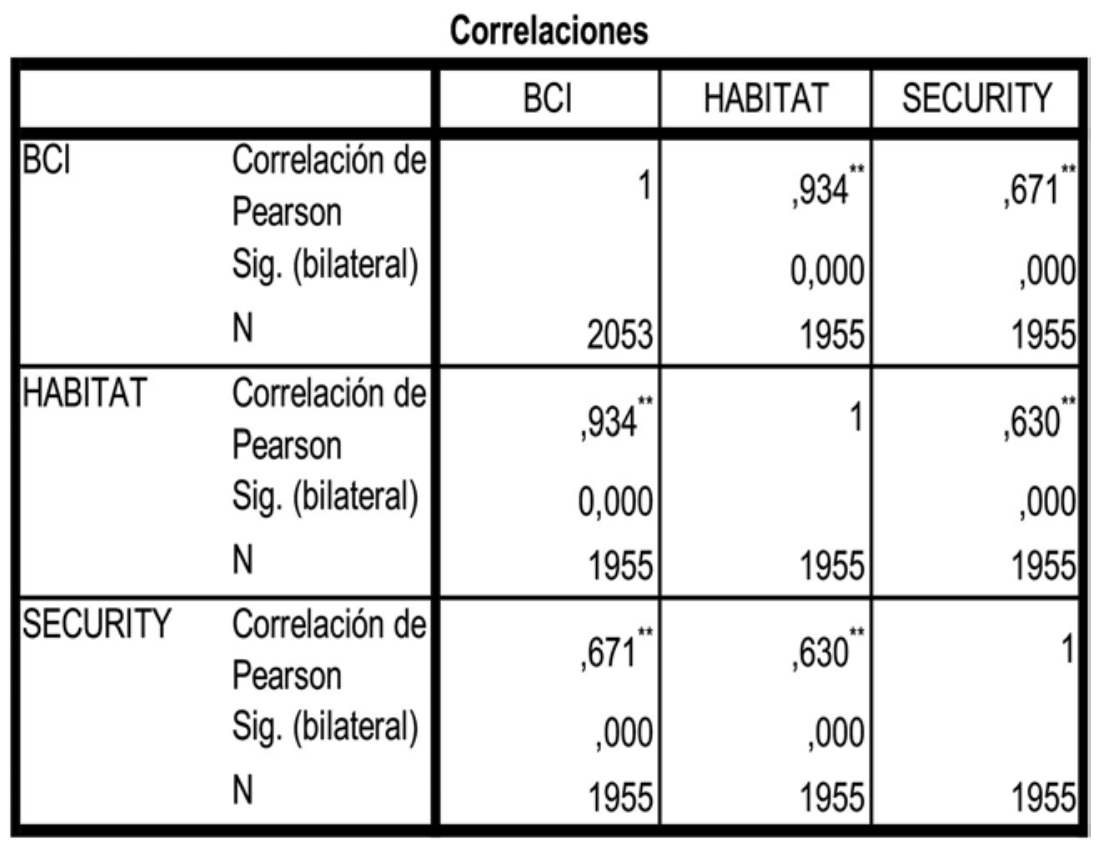

Fuente: Elaboración propia en base a la información proporcionada por la Bolsa de Comercio de Santiago

Al comparar BCI con HABITAT, se obtiene un índice de correlación de 0,934, el cual indica que existe correlación entre el valor de las acciones. Al comparar HABITAT con SECURITY, se obtiene un índice de correlación de 0,630, el cual indica que existe correlación entre el valor de las acciones. Y por último al comparar SECURITY con $\mathrm{BCl}$, se obtiene un índice de correlación de 0,671 , el cual indica que existe correlación entre el valor de las acciones. 


\section{Análisis del Sector Tecnología y Telecomunicaciones}

Sexto Sector Económico: empresas Entel y Sonda (2005-2014)

\section{ENTEL}

Gráfico 16: Comportamiento de las acciones de ENTEL.

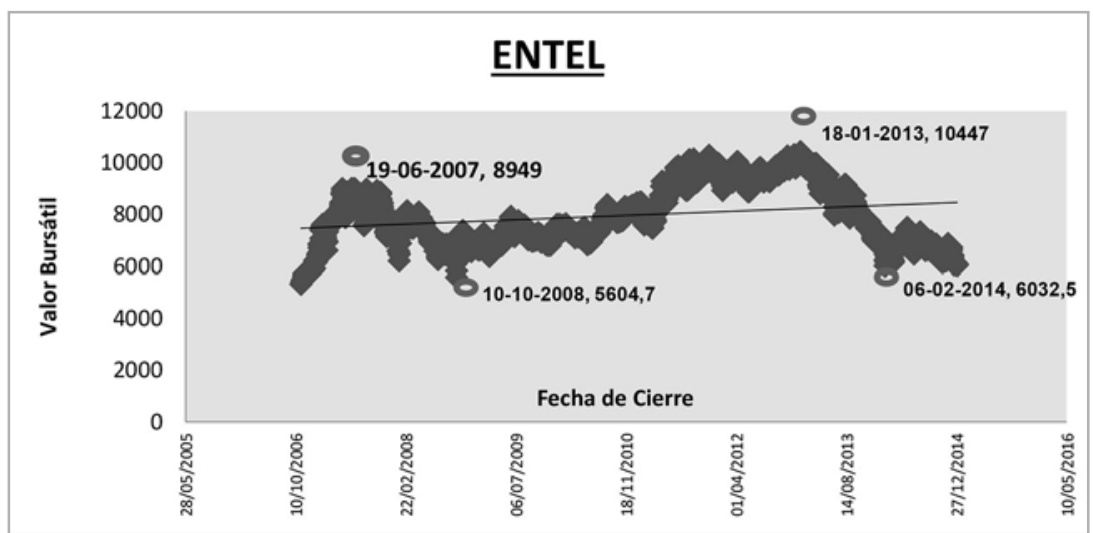

Fuente: Elaboración propia en base a la información proporcionada por la Bolsa de Comercio de Santiago.

2005: Lanzó nuevos servicios de valor agregado, Black Tones y BlackBerry. Ampliaron cobertura, siendo la primera compañía en entregar servicios de telefonía móvil en el continente antártico.

2006: Se acuerda crear nueva Soc. Anónima Cerrada, en donde participará como accionista mayoritario. La principal actividad de esta sociedad será la comercialización de las tarjetas de servicio telefónico prepago.

2007: Generó modelos que permiten una mejor atención, ampliando la capacidad de su red y brindando una gran gama de servicios innovadores de valor agregado. También existió un crecimiento en el ingreso promedio por cliente.

2008: Adquirió Cientec Computación S.A., empresa de alto prestigio y prestador líder de servicios de continuidad operacional. Continuó con su agresivo plan de inversiones, alcanzando un monto de USD 352 millones para infraestructura que sustentan el incremento en capacidad de la red móvil, mayor cobertura de la red de banda ancha móvil

2009: Pese a los efectos negativos de la crisis internacional, la economía chilena y de la reducción en los cargos de accesos móviles, los resultados obtenidos por la empresa pudieron evaluarse positivamente. Se inició la comercialización del 
dispositivo IPhone 3GS, de alta aceptación dentro de los segmentos de alto valor de la compañía. Los Estados Financieros de la compañía, fueron elaborados por primera vez bajo IFRS.

2010: El terremoto afectó la póliza correspondiente a los Bienes Físicos y el Perjuicio por Paralización. El siniestro provocó daños materiales a más de un millar de sitios técnicos de la empresa, daños en inventario de equipos depositados en bodega y en algunas edificaciones, representó pérdidas, las que tuvieron cobertura a través de la póliza vigente al momento del siniestro con las compañías de seguros RSA en coaseguro con Chartis.

2011: La inversión en equipos móviles para el segmento de suscripción alcanzó un monto de US $\$ 230$ millones, el cual está relacionado con el desarrollo de Internet móvil sobre teléfonos inteligentes (smartphones).

2012: La entrada en vigencia de la Portabilidad Numérica y la contratación de planes de Internet Móvil sobre smartphones, marcó un escenario de exigencia y actividad comercial.

2013: Establecieron provisoriamente nueva política de dividendos consistente en el reparto de hasta el $50 \%$ de las utilidades distribuibles. Registró una utilidad de un $12 \%$ inferior a la obtenida en el año anterior, generada principalmente por el efecto del cambio en el tratamiento contable de los equipos móviles en arriendo para clientes de post pago.

2014: La utilidad tuvo una disminución de $62 \%$ comparado con la del año anterior. La industria decreció 2,5\% a diciembre de 2014, afectada por la caída en la tarifa de interconexión o cargo de acceso, una mayor madurez en el mercado y por el contexto económico del año. Se finalizó la implementación que elimina la Larga Distancia Nacional. 


\section{SONDA}

Gráfico 17: Comportamiento de las acciones de SONDA.

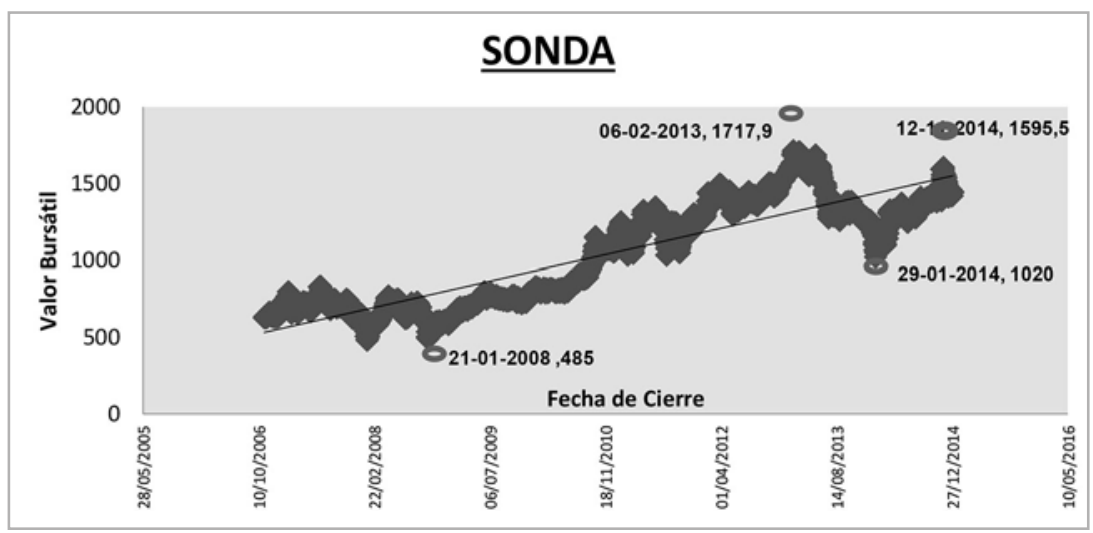

Fuente: Elaboración propia en base a la información proporcionada por la Bolsa de Comercio de Santiago.

2006: Decidió abrirse a la Bolsa, teniendo una demanda de US\$ 6.000 millones, 28 veces el monto de la colocación, en un mercado con escasa presencia bursátil de empresas de tecnología. Firmó un contrato con Petrobras para proveer soporte tecnológico y HelpDesk a 45.000 usuarios de TI y 27.000 usuarios de SAP.

2007: Adquisición del $100 \%$ de la empresa Procwork, una de las firmas de servicios de TI más importantes de Brasil. El 2007 trajo dificultades, derivadas principalmente de la participación como operador tecnológico del Transantiago.

2008: Uno de los proyectos más emblemáticos emprendido por la empresa en los últimos años es la operación tecnológica de Transantiago, un contrato de servicios a 12 años con ingresos recurrentes, provocó un entorno de dificultades comunicacionales y políticas.

2009: A pesar de la crisis mundial que golpeó severamente a los países latinoamericanos. Al finalizar este ejercicio, la entidad anuncio un plan de inversiones por US\$ 500 millones para el trienio 2010-2012, lo que constituye el escalón siguiente al plan 2007- 2009.

2010: Empresas adquiridas por la compañía en el año: Softeam, Telsinc y Kaizen en Brasil, NextiraOne en México y Ceitech en Argentina, siendo tres de ellas actores relevantes en el negocio de virtualización, comunicaciones y cloudcomputing en Latinoamérica. También suscribieron una con Autodesk, empresa líder en software para ingeniería y diseño 3D. 
2011: Durante el ejercicio sobrepasaron los US\$ 1.000 millones en ingresos, alcanzando cifra récord de $\$ 592.819$ millones, lo que representa un alza de $33,1 \%$. En septiembre se culminó la Oferta Pública de Adquisición de Quintec.

2012: Aumento de capital permitió recaudar US\$ 301 millones por un total de 100.000 .000 nuevas acciones emitidas. Puesta en marcha del proyecto Metrobus en la ciudad de Panamá. Durante 2012 finalizaron la construcción del nuevo Datacenter de SONDA.

2013: Concluyó el aumento de capital por US $\$ 300$ millones, con el fin de financiar parte del plan de inversiones del trienio 2013-2015. Inauguraron un nuevo Datacenter en Chile, obra que demandó una inversión de US\$ 33 millones y que se suma al de Brasil.

2014: América Latina enfrentó un año 2014 que trajo consigo dificultades producto de la desaceleración de la economía mundial.

Aplicación y Análisis prueba de Kolmogorov-Smirnov para Sector Tecnología y Telecomunicaciones.

Cuadro 14: Prueba de Kolmogorov-Smirnov del Sector Tecnología y Telecomunicaciones.

Prueba de Kolmogorov-Smirnov para una muestra

\begin{tabular}{|ll|r|r|}
\hline & & ENTEL & \multicolumn{1}{|c|}{ SONDA } \\
\hline $\mathrm{N}$ & 2127 & 2127 \\
Parámetros & Media & 9078,266 & 957,365 \\
normales $^{\mathrm{a}, \mathrm{b}}$ & Desviación & 5190,277 & 385,221 \\
& estándar &, 364 &, 145 \\
Máximas & Absoluta &, 364 &, 145 \\
diferencias & Positivo &,- 261 &,- 116 \\
extremas & Negativo &, 364 &, 145 \\
Estadístico de prueba &, $112^{\mathrm{c}}$ &, $123^{\mathrm{c}}$ \\
\hline
\end{tabular}

Fuente: Elaboración propia en base a la información proporcionada por la Bolsa de Comercio de Santiago.

Puesto que el valor del nivel crítico (Sig. Asintótica bilateral) es mayor a los grados de significancia $(0,05)$, se acepta la hipótesis de normalidad para el Sector Tecnología 
y Telecomunicaciones y se concluye que la muestra se ajusta a una distribución normal donde la prueba más acorde a esta distribución es la de Pearson.

Aplicación y Análisis prueba de Pearson para Sector Tecnología y Telecomunicaciones. Cuadro 15: Prueba Correlación Pearson del Sector Tecnología y Telecomunicaciones.

\begin{tabular}{|ll|r|r|}
\hline \multicolumn{2}{|c|}{ Correlaciones } \\
\hline ENTEL & \multicolumn{1}{|c|}{ ENTEL } & \multicolumn{1}{|c|}{ SONDA } \\
& Correlación de & 1 &, $569^{* *}$ \\
& Pearson &, 000 \\
& Sig. (bilateral) & & 2029 \\
& $N$ & 2029 & 1 \\
\hline SONDA & Correlación de &, $569^{* *}$ & \\
& Pearson &, 000 & 2029 \\
& Sig. (bilateral) & 2029 & \\
& $N$ & & \\
& $N$ &
\end{tabular}

Fuente: Elaboración propia en base a la información proporcionada por la Bolsa de Comercio de Santiago.

Al comparar ENTEL con SONDA, se obtiene un índice de correlación de 0,569, el cual indica que existe correlación entre el valor de las acciones. 


\section{DISCUSIÓN DE RESULTADOS}

Sector Petróleo y Energía, se puede apreciar que la correlación que existe entre las empresas; Colbún, Endesa y Enersis, corresponde a una correlación cuyos índices son mayores a 0,5, esto quiere decir que, si se toma como referencia el comportamiento del grupo 1, las acciones en su conjunto indican que existe correlación, o sea, se cumple con lo que se busca en la investigación que es que las empresas tienen el mismo comportamiento en sus acciones ante un mismo hito económico. Descrito lo anterior, la evidencia recogida, una vez analizada cada empresa perteneciente a este grupo, indica que la hipótesis planteada se cumple.

Sector Materiales Básicos, Industria y Construcción, se puede apreciar que la correlación que existe entre las empresas Besalco, CMPC y SQM, corresponde a una correlación cuyos índices son mayores a 0,5 , esto quiere decir que, si se toma como referencia el comportamiento del grupo 2, las acciones en su conjunto indican que existe correlación, o sea, se cumple con lo que se busca en la investigación que es que las empresas tienen el mismo comportamiento en sus acciones ante un mismo hito económico. Descrito lo anterior, la evidencia recogida, una vez analizada cada empresa perteneciente a este grupo, indica que la hipótesis planteada se cumple.

Sector Bienes de Consumo, se puede apreciar que la correlación que existe entre las empresas; Embonor, Concha y Toro y CCU, corresponde a una correlación cuyos índices no se comportan de la misma manera entre estas 3 empresas. Entre Embonor y Concha y Toro corresponde a una correlación cuyos índices son menores a 0,5 , esto quiere decir que, no existe correlación entre ellas, 0 sea no se cumpliría con el planteamiento de la hipótesis. Lo mismo ocurriría con la relación entre Concha y Toro y CCU, dado que los índices también son menores a 0,5, lo que significa que no existe relación entre las empresas. Por el contrario, entre las empresas CCU y Embonor existe correlación, ya que sus índices son mayores 0,5 . Descrito lo anterior, la evidencia recogida, una vez analizada cada empresa perteneciente a este grupo, indica que la hipótesis planteada no se cumple.

Sector Servicios de Consumo, se puede apreciar que la correlación que existe entre las empresas; Cencosud, Ripley y Falabella, corresponde a una correlación cuyos índices no se comportan de la misma manera. Entre Cencosud y Ripley corresponde a una correlación cuyos índices son mayores a 0,5, esto quiere decir que, existe correlación entre ellas, o sea se cumpliría con el planteamiento de la hipótesis. Lo mismo ocurriría con la relación entre Falabella y Cencosud, dado que 
los índices también son mayores a 0,5, lo que significa que existe relación entre las empresas. Por el contrario, entre las empresas Ripley y Falabella no existe correlación, ya que sus índices son menores a 0,5. Descrito lo anterior, la evidencia recogida, una vez analizada cada empresa perteneciente a este grupo, indica que la hipótesis planteada no se cumple.

Sector Servicios Financieros e Inmobiliarios, se puede apreciar que la correlación que existe entre las empresas; $\mathrm{BCl}$, Habitad y Security, corresponde a una correlación cuyos índices son mayores a 0,5, esto quiere decir que, si se toma como referencia el comportamiento del grupo 5 , las acciones en su conjunto indican que existe correlación, o sea, se cumple con lo que se busca en la investigación que es que las empresas tienen el mismo comportamiento en sus acciones ante un mismo hito económico. Descrito lo anterior, la evidencia recogida, una vez analizada cada empresa perteneciente a este grupo, indica que la hipótesis planteada se cumple.

Sector Tecnología y Telecomunicaciones, se puede apreciar que la correlación que existe entre las empresas; Entel y Sonda, corresponde a una correlación cuyos índices son mayores a 0,5, esto quiere decir que, si se toma como referencia el comportamiento del grupo 6, las acciones en su conjunto indican que existe correlación, o sea, se cumple con lo que se busca en la investigación que es que las empresas tienen el mismo comportamiento en sus acciones ante un mismo hito económico.

Con respecto a los hitos económicos que tuvieron un impacto significativo en la valoración de las acciones en las empresas con mayores transacciones bursátiles de los 6 sectores económicos nombrados anteriormente, se pueden identificar: Burbuja Inmobiliaria, Crisis Financiera Subprime, Crisis Europea, Desaceleración en China y el Terremoto y Tsunami en Centro Sur (febrero 2010). Se pudo apreciar en la mayoría de los sectores económicos una tendencia entre las empresas de cada sector. 


\section{CONCLUSIÓN}

El comportamiento que sufren las acciones se ven relacionadas, en gran medida, por las contingencias económicas tanto nacionales como internacionales, pero también por diversos hitos económicos que pueden afectar al país en donde se transan dichas acciones.

En lo que respecta a la correlación por sector industrial, el precio de las acciones experimenta las mismas variaciones frente a los principales hitos económicos identificados, se pudo observar en los resultados que, en la gran mayoría de los grupos, existe correlación entre las distintas entidades que conforman cada grupo económico. Sin embargo, en los grupos 3 y 4 no existe. Con lo anterior, se pudo determinar que no existe un mismo comportamiento entre los grupos económicos y las entidades correspondientes.

Se pudo determinar que el sector industrial que más resultó afectado en relacióncon el valor de sus acciones, fue el Sector de Servicios de Consumo compuesto por empresas de retail con caídas de hasta un $70 \%$ en el valor de sus acciones y alzas de $500 \%$. Cabe destacar que, entre los hitos económicos que tuvieron un mayor impacto sobre la valoración de las acciones, sobresalen las bruscas caídas que sufrieron las acciones tras la crisis Subprime del 2008, las alzas en los precios en el año 2010 producto del terremoto del 27 de febrero y declines de acciones desde los años 2012 en adelante. También se puede concluir que otro de los Sectores afectados fue el de Materiales Básicos, Industriales y Construcción. Se detecta que existieron otros hitos económicos no identificados en la investigación y que afectaron de manera significativa a algunos grupos económicos. Entre los cuales cabe destacar:

Grupo 1 "Sector Petróleo y Energía", el factor más importante que lo afectó fue la gran sequía existente en el país a partir del año 2008 hasta principios del 2014. También el aumento que tuvo el costo del gas argentino debido a su escasez, lo que provocó que las entidades tuvieran que invertir en otro tipo de combustible.

Grupo 2 "Sector Materiales Básicos, Industria y Construcción", tales como, incendios forestales, aumento del costo del gas natural y aumento en el precio del petróleo. Con menor impacto, que en el caso del grupo 1.

No obstante, también existieron hitos económicos que afectaron a la gran mayoría de los sectores industriales y a cada una de las empresas que lo componen como 
Ia Crisis Financiera Subprime, Crisis Europea y el Terremoto del 27 de febrero del 2010.

Cabe destacar que, entre los grupos económicos analizados en la investigación, se pudo detectar que el sector industrial con más correlación fue el Grupo №1 "Sector Petróleo y Energía”, conformado por las empresas Colbún, Endesa y Enersis.

Finalmente, la hipótesis planteada y objeto de la investigación, que afirma que: "Frente a un mismo hito económico el precio de las acciones experimenta las mismas variaciones en cada sector industrial". Luego del estudio realizado, se pone de manifiesto que se RECHAZA, dado que un mismo hito económico no afectó de la misma manera a todos los grupos económicos de los diversos sectores industriales. Lo anterior debido a que dos grupos económicos no tuvieron correlación entre las empresas que lo compañía.

Sin embargo, se puede plantear una hipótesis alternativa, la cual sería: "Frente a un mismo hito económico el precio de las acciones experimenta las mismas variaciones en la mayoría de los sectores industriales". 


\section{BIBLIOGRAFÍA}

- Aquevedo, E. (2014). Chile: terremoto del 27 de Febrero del 2010. Aquevedo, E.

- Barcelata. H, (2010). Chile: La crisis financiera en estados unidos. Eumed.net.

- Biblioteca Nacional de Chile (2014). Chile. Memoria Chilena: Biblioteca Nacional de Chile. Ministerio de Educación.

- Blas, R., (2013). Chile. Crisis Europea, Crisis del Capitalismo: Causas y Efectos. Buenas Prácticas.

- Bolsa de Comercio de Santiago, (2015).Chile: Como Invertir. Banco de Comercio de Santiago.

- Brigham, E., Houston, J. (2005). Mexico: Administration Financiera. Cengage Learning.

- Caputo,0. (2009). Chile: El país más afectado por la crisis económica en América latina. Rel.Uita.

- CNN, (2012). España. Sismo de magnitud 7,1 sacude el centro de Chile. CNN. Disponible en: http://cnnespanol.cnn.com/2012/03/25/sismo-de72-grados-sacude-centro-de-chile/. Consultado [10 de junio del 2015].

- Comisión Europea, (2014). España. ¿Por qué se originó la crisis europea? Comisión Europea. Disponible en: http://ec.europa.eu/economy_finance/ explained/the_financial_and_economic_crisis/why_did_the_crisis_ happen/index_es.htm. Consultado [26 de Mayo del 2015].

- Emol, (2015). Chile. Grandes Terremotos Chileno. Emol. Disponible en: http://www.emol.com/especiales/terremotos/chile.htm. Consultado [2 de Junio del 2015]

- Foley, J. (2013). México. China, lecciones de la desaceleración. CNN Expansión.

- Hernández. A; Moraleda. B; Sánchez. M. (2011). España: Crisis económicas a lo largo de la historia. Instituto de Estudios Fiscales.

- Interpatagonia, (2015). Chile Chaitén Interpatagonia. Disponible en: http:// www.interpatagonia.com/chaiten/. Consultado [10 de Junio del 2015].

- Ministerio de Hacienda, (2015). ¿Qué es el mercado de capitales 
chilenos? Ministerio de Hacienda. Chile.

- Ross, S. Westerfield, R., Jaffe, J. (2009) México: Finanzas Corporativas. McGraw Hill. 